\title{
BOWING OF MARBLE SLABS: CAN THE PHENOMENON BE ARRESTED AND PREVENTED BY INORGANIC TREATMENTS?
}

\author{
Enrico Sassoni ${ }^{1}{ }^{*}$, Serena Andreotti ${ }^{1}$, George W. Scherer ${ }^{2}$, Elisa Franzoni ${ }^{1}$, \\ Siegfried Siegesmund ${ }^{3}$ \\ ${ }^{1}$ Department of Civil, Chemical, Environmental and Materials Engineering (DICAM), \\ University of Bologna, Via Terracini 28,40131 , Bologna, Italy \\ ${ }^{2}$ Department of Civil and Environmental Engineering (CEE), \\ Princeton University, 69 Olden Street, 08542, Princeton (NJ), U.S.A. \\ ${ }^{3}$ Department of Department of Structural Geology and Geodynamics \\ University of Göttingen, Goldschmidtstr. 3, 37077, Göttingen, Germany \\ * corresponding author: enrico.sassoni2@unibo.it
}

\begin{abstract}
Bowing of thin marble slabs is a phenomenon affecting both historic monuments and modern buildings. In spite of the ubiquity and destructiveness of this phenomenon, no fully satisfactory treatment is currently available to arrest and/or prevent bowing. In this study, a treatment based on formation of hydroxyapatite (HAP) was investigated as a possible route to arrest and possibly prevent bowing of Carrara marble slabs. Four different formulations of the HAP-treatment were tested and compared to ammonium oxalate and ethyl silicate (widely used in the practice of marble conservation). The treatments were applied onto pre-weathered and unweathered specimens to investigate their ability to arrest and prevent bowing, respectively. Marble behavior was studied in terms of residual strain and bowing after thermal cycles up to $90^{\circ} \mathrm{C}$ in dry and wet conditions. Marble cohesion was assessed before and after the thermal cycles by ultrasound. The HAP-treatments exhibited promising results, as the residual strain and the bowing after the cycles were always lower or equal to the untreated references, while marble cohesion was always higher. Surprisingly, ammonium oxalate caused marked worsening of marble thermal behavior. In the case of ethyl silicate, most of the initial benefit after consolidation was lost after the thermal cycles. In general, the results of the study point out the importance of evaluating marble thermal behavior to assess the suitability of any conservation treatment and suggest that treatments able to strengthen marble without causing excessive pore occlusion and stiffening are preferable to enhance durability to thermal cycles.
\end{abstract}

\section{KEYWORDS}

Warping; Marble; Hydroxyapatite; Calcium oxalate; Thermal behavior; Thermal weathering 


\section{INTRODUCTION}

Bowing of thin marble slabs is a phenomenon affecting both historic monuments and modern buildings (Kieslinger, 1934; Grimm, 1999; Marini and Bellopede, 2009; Royer Carfagni, 1999; Siegesmund et al., 2000; Siegesmund et al., 2008) (Fig. 1). Slabs used as gravestones in monumental cemeteries and commemorative stones in historic buildings often exhibit severe bowing, frequently leading to fracturing and collapse (Sassoni and Franzoni, 2014a). Thin slabs used to clad modern façades may exhibit bowing as well, typically some 10-15 years after construction (Jounet et al., 2002; Malaga-Starzec et al., 2006), and bowing has even been reported after only 1 year (Malaga-Starzec et al., 2002). Among modern buildings, the Finland Hall in Helsinki by Alvar Aalto (Royer Carfagni, 1999) and the Amoco Building in Chicago (Siegesmund et al., 2000) are famous examples where bowing of the slabs used to clad the external surfaces was so pronounced that their entire replacement was necessary. In the case of the Amoco Building, this cost as much as \$ 65 million (Siegesmund et al., 2000).

The origins of the bowing phenomenon are quite controversial. The release of locked residual stresses (Logan et al., 1993; Royer Carfagni, 1999; Siegesmund et al., 2008), the presence of moisture (Koch and Siegesmund, 2004; Siegesmund et al., 2008) and the attack by acid rain (Grimm, 1999; Royer Carfagni, 1999) have been proposed as possible factors initiating bowing. However, it is commonly recognized that thermal excursions play a very important role (Rayleigh, 1934; Royer Carfagni, 1999; Siegesmund et al., 2000; Siegesmund et al., 2008; Malaga-Starzec et al., 2006).

Because of the anisotropic thermal expansion of calcite crystals upon temperature variations, when marble is exposed to repeated heating-cooling cycles, micro-cracks develop at the boundaries between grains (Siegesmund et al., 2000; Shushakova et al., 2013a; Shushakova et al., 2013b; Weiss et al., 2003). In the case of slabs, a temperature gradient may develop between the external side of the slab, directly exposed to air temperature variations and possibly to direct solar radiation, and the internal side, more protected from temperature excursions. This gradient in temperature between the two sides of a slab may lead to a gradient in the amount of cracks among grains. The external side, more affected by micro-cracking, tends to expand, but it is constrained by the internal side, which tends to preserve the original size. As a result, convex bowing towards the exterior arises (Rayleigh, 1934). Accordingly, it was shown by mercury intrusion porosimetry that the external side of convexly bowed slabs has higher porosity and coarser pores than the internal side (Koch, 2006) and that porosity and pore size increase with increasing level of bowing (Siegesmund et al., 2008).

In spite of the ubiquity and the destructiveness of the bowing phenomenon, only a few studies have investigated possible treatments to mitigate marble thermal weathering (Malaga et al., 2004; Malaga-Starzec et al., 2006; Ruedrich et al., 2002; TEAM project, 2005). The EU-funded TEAM project (2005) investigated the use of microcrystalline wax, colloidal silica, an hydrophobic acrylic 
product and an hydrophobic siloxane product to reduce bowing. Even if the treatments were able to reduce bowing to some extent (Malaga et al., 2004), impregnation by these products did not prevent strength loss after thermal cycles (TEAM project, 2005). In the case of marble impregnated with polymethyl-methacrylate, the residual strain after thermal cycles was found to be even higher than in the untreated marble (Ruedrich et al., 2002; Siegesmund et al., 1999), with possible acceleration of marble deterioration.

In this study, a treatment based on hydroxyapatite (HAP), recently proposed for protection of marble (Graziani et al., 2016; Naidu et al., 2011; Naidu et al., 2016; Possenti et al., 2016; Sassoni et al., 2018a; Yang and Liu, 2014) and consolidation of marble and limestone (Liu and Zhang, 2011; Ma et al., 2017; Matteini et al., 2011; Molina et al., 2017; Sassoni and Franzoni, 2014a; Sassoni et al., 2015; Sassoni et al., 2018a; Yang et al., 2011), was investigated as a possible route to arrest and prevent bowing of thin marble slabs. The treatment was originally developed to create an insoluble, protective layer of HAP on marble, taking advantage of the much lower solubility and slower dissolution rate of HAP compared to calcite (Naidu et al., 2011; Naidu and Scherer, 2014). HAP can be formed from the reaction between $\mathrm{PO}_{4}{ }^{3-}$ ions coming from an aqueous solution of diammonium hydrogen phosphate $\left(\mathrm{DAP},\left(\mathrm{NH}_{4}\right)_{2} \mathrm{HPO}_{4}\right)$, that marble is treated with, and $\mathrm{Ca}^{2+}$ ions coming from marble dissolution and/or externally added to the DAP solution (Naidu and Scherer, 2014; Sassoni et al., 2011). Several different formulations of the treatment have been developed through the years, to improve the HAP layer microstructure (absence of cracks and pores) and composition (absence of metastable calcium phosphate phases), providing promising results (Graziani et al., 2016; Naidu and Scherer, 2014; Sassoni et al., 2015; Sassoni, 2017; Sassoni et al., 2018a). The treatment also demonstrated a remarkable ability to consolidate weathered marble, thanks to HAP formation inside the micro-cracks between calcite grains. This leads to more effective bonding of grains and improved mechanical properties (Sassoni and Franzoni, 2014a; Sassoni et al., 2015; Sassoni et al., 2018a). In a previous study by the Authors (Sassoni et al., 2017), marble thermal behavior after application of the HAP-treatment was investigated and encouraging results were found. The residual strain after thermal cycles was found to be reduced in treated marble, which implies better behavior in terms of resistance to bowing (Sassoni et al., 2017). However, in the cited study no direct measurement of the tendency of marble to bow was performed.

In the present study, dilatometric tests and direct bowing measurements were carried out to estimate: (i) the ability of the HAP-treatment (tested in 4 formulations and compared to ammonium oxalate and ethyl silicate) to arrest further bowing of already bowed slabs; (ii) the ability of the most promising HAP-treatment formulation (as assessed by preliminary dilatometric tests) to prevent bowing of unweathered marble. A scheme illustrating the rationale of the study is reported in Fig. 2 . 


\section{MATERIALS AND METHODS}

\subsection{Marble}

A particular type of Carrara marble ("Gioia Venato"), known to undergo severe bowing (Jornet et al., 2002; Logan, 2004; Siegesmund et al., 2008), was selected for the tests. From a single block (supplied by Elle Marmi s.r.I., Italy), slabs with $40 \times 10 \times 2 \mathrm{~cm}^{3}$ size were obtained for the bowing tests. The slabs were sawn along two orthogonal directions, parallel ("verso") and perpendicular ("contro") to foliation, to evaluate warping behavior in different directions. From a $10 \mathrm{~cm}$-cube, cylindrical specimens $(1.5 \mathrm{~cm}$ diameter, $5 \mathrm{~cm}$ height) were core-drilled for the dilatometric tests, again along the "verso" and "contro" directions.

\subsection{Chemicals}

For the treatments, diammonium hydrogen phosphate (DAP, $\left(\mathrm{NH}_{4}\right)_{2} \mathrm{HPO}_{4}$, assay $>99 \%$, FisherScientific), calcium chloride $\left(\mathrm{CaCl}_{2} \cdot 2 \mathrm{H}_{2} \mathrm{O}\right.$, assay $>99 \%$, Fisher-Scientific), ethanol (EtOH, FisherScientific), isopropanol (IPA, Fisher-Scientific), calcium hydroxide $\left(\mathrm{Ca}(\mathrm{OH})_{2}\right.$, Fisher-Scientific), ammonium oxalate $\left(\left(\mathrm{NH}_{4}\right)_{2} \mathrm{C}_{2} \mathrm{O}_{4} \cdot \mathrm{H}_{2} \mathrm{O}\right.$, assay $>99 \%$, Fisher-Scientific) were used. For the treatment based on ethyl silicate, the commercial product Estel 1000 by CTS s.r.I. (Italy) was used. The product is composed of $75 \mathrm{wt} \%$ ethyl silicate (also containing 1\% dibutyltin dilaurate as catalyst) and $25 \mathrm{wt} \%$ white spirit. All water was deionized.

\subsection{Preliminary weathering}

To evaluate the ability to arrest bowing, for each treatment condition and each direction two slabs and one cylinder were preliminarily artificially aged, so as to apply the consolidants on already bowed/already thermally damaged specimens (Fig. 2). In this phase of the study the aim was not to reproduce realistic weathering conditions, but only to cause realistic damage as quickly as possible, so the specimens were subjected to severe, unrealistic conditions, as described in the following.

To produce bowed specimens, 28 slabs (14 for each direction) were subjected to thermal cycles using the apparatus illustrated in Fig. 3a,b. Each cycle consisted in heating to $120^{\circ} \mathrm{C}$ for $70 \mathrm{~min}$, then cooling for at least 5 hours. The temperature at the two sides of the specimens (i.e., the upper side facing the lamps, "Top", and the lower side in contact with water, "Bottom") was measured by an infrared gun at 10 min intervals during the test. The variation in temperature at the two sides as a function of time is plotted in Fig. 3,c. The high maximum temperature ensured severe damage and the rapid heating ensured a big thermal gradient between the two sides of the slabs. The thermal cycles were repeated until bowing reached $1.1 \pm 0.1 \mathrm{~mm} / \mathrm{m}$. This level of bowing was selected based 
on data obtained in a previous study (Siegesmund et al., 2008) for the same type of marble (Gioia Venato): at about this level of damage, the bowing rate started to slow down (although bowing kept on increasing slowly). In the present study, this level of bowing was chosen as the moment to stop the preliminary weathering cycles and to apply the consolidants because, if a higher initial level of damage had been reached, the risk of entering the phase of "slower bowing" would have risen. In such a case, the effects of the consolidants would have become less clear and less easy to evaluate, because in this phase even untreated marble exhibits a slower bowing rate (even though bowing keeps on increasing). Bowing (i.e., deviation from planarity) was determined by measuring the displacement in the middle, using a gauge with $0.5 \mu \mathrm{m}$ accuracy and a metal frame to ensure the measurement was carried out always exactly in the sample position, as described in EN16306 (2013). The desired level of preliminary bowing was reached after $17 \pm 2$ cycles, the number varying because heating is not perfectly uniform among all the specimens during the test. In fact, the central specimens receive heat from more than one lamp at a time (Fig. 3a,b), thus experiencing more damage in a single cycle. To minimize the difference in damage among different specimens, their positions were switched after each cycle, so that after 6 cycles each specimen had sat once in each position inside the box. At the end of the thermal cycles, the residual dynamic elastic modulus $\left(E_{d}\right)$ of the slabs was determined, as described in $\S 2.5 .1$. The aim was to quantify the level of mechanical damage experienced by the slabs, so that it could be reproduced also in the cylinders to be used for the dilatometric tests.

Once assessed the residual $E_{d}$ of the slabs ( $30 \%$ of the initial value), preliminary tests were carried out to identify the heating conditions (temperature and time) necessary to reproduce in an accelerated way the same level of damage in the cylinders. Consistent with the temperature- $E_{d}$ relationship determined in a previous study on Carrara marble (Figure 7 in Sassoni et al., 2018b), heating in an oven at $100{ }^{\circ} \mathrm{C}$ for $1 \mathrm{~h}$ caused an $E_{d}$ decrease to $\sim 60 \%$ of the initial value, while heating at $200{ }^{\circ} \mathrm{C}$ for $1 \mathrm{~h}$ caused a further reduction to $\sim 30 \%$ of the initial value. As this was the same reduction in $E_{d}$ experienced by the slabs subjected to the preliminary bowing cycles, these conditions were selected for accelerated ageing of the cylinders for the dilatometric tests (Fig. 2). In total, 14 cylinders ( 7 for each direction) were heated to $200^{\circ} \mathrm{C}$ for 1 hour in an oven. The reason why a higher heating temperature was necessary in the case of the cylinders $\left(200^{\circ} \mathrm{C}\right)$ compared to the slabs $(120$ ${ }^{\circ} \mathrm{C}$ ) is to be found in the different heating duration ( $1 \mathrm{~h}$ for the cylinders against 17 cycles of heating for $70 \mathrm{~min}$ for the slabs).

\subsection{Treatments}

The 7 treatment conditions (including the untreated reference) listed in Table 1 were applied to: (i) the 28 bowed slabs and the 14 thermally damaged cylinders, with the aim of evaluating the ability of the treatment to arrest bowing; (ii) 14 unweathered cylinders, with the aim of evaluating the ability to 
This is a post-peer-review, pre-copyedit version of the article: Sassoni E., Andreotti S., Scherer G.W., Franzoni E., Siegesmund S., Bowing of marble slabs: can the phenomenon be arrested and prevented by inorganic treatments?, Environmental Earth Sciences 77 (2018) 387. The final version is available online at DOI: 10.1007/s12665-018-7547-7

prevent bowing. For the latter purpose, 2 unweathered slabs ( 1 for each direction) were subjected to the "1 M DAP" treatment, while 2 unweathered slabs were left untreated and used as reference. The "1 M DAP" treatment was selected based on results of dilatometric tests on unweathered cylinders, as this treatment provided the highest $E_{d}$ increase after consolidation (cf. § 3.2).

The treatment solutions were prepared as described in detail in previous studies by Sassoni et al. (2018) for treatments "EtOH", "IPA" and "1 M DAP"; Franzoni et al. (2015a) for "3 M DAP"; Sassoni et al. (2015) for "AmOx" and "ES". In brief, the "1 M DAP" treatment (the first one proposed by Naidu and Scherer (2014)) involves a relatively high DAP concentration (1 M), to ensure that enough $\mathrm{PO}_{4}{ }^{3-}$ ions are available to form HAP. It also involves addition of a calcium source $\left(\mathrm{CaCl}_{2}\right.$, in 1:1000 molar ratio to DAP), to favor complete coverage of marble by the new calcium phosphates (Naidu and Scherer, 2014). The "EtOH" and "IPA" treatments involve addition of 10 vol\% of the respective alcohols, with the aim of increasing the amount of $\mathrm{PO}_{4}{ }^{3-}$ ions dissociated from DAP, thanks to the weakening effect of alcohols on the hydration sphere of $\mathrm{PO}_{4}{ }^{3-}$ ions in the solution (Sassoni et al., 2018a). This results in a continuous, crack-free and pore-free coating, even at low DAP and $\mathrm{CaCl}_{2}$ concentrations ( $0.1 \mathrm{M}$ and $0.1 \mathrm{mM}$, respectively) (Sassoni et al., 2018a). The "3 M DAP" treatment involves a high DAP concentration, close to saturation, as an alternative way to increase the amount of $\mathrm{PO}_{4}{ }^{3-}$ ions available to form HAP (although, in these conditions, the resulting coating is thick and cracked) (Sassoni et al., 2015). This treatment also involves application of a limewater poultice as a second step after DAP application and drying, with the aim of supplying additional $\mathrm{Ca}^{2+}$ ions for the reaction and removing unreacted DAP during drying (Franzoni et al., 2015a; Graziani et al., 2017). In all cases where $\mathrm{CaCl}_{2}$ was added as an external calcium source (namely, treatments "1 M DAP", "EtOH" and "IPA"), no risk owing to formation of harmful chloride salts is expected. In fact, in previous studies where $0.1 \mathrm{mM} \mathrm{CaCl}_{2}$ was added to a 0.1 M DAP solution (treatments "EtOH" and "IPA"), no chloride trace was found by either XRD or EDS, which indicates that all the chlorides (present only in millimolar concentration) were effectively removed by rinsing with water at the end of the treatment (Sassoni et al., 2018a). When $1 \mathrm{mM} \mathrm{CaCl}_{2}$ was added to a $1 \mathrm{M}$ DAP solution (treatment "1 M DAP"), no trace of chloride salts was detected by XRD (Naidu and Scherer, 2014) and only in a few cases (but not systematically) a small chloride peak was found by EDS (Naidu et al., 2015). Because the chloride peak in the EDS spectrum appeared even after extensive rinsing with water, chlorides are thought to be incorporated in the HAP crystal, that easily undergoes ionic substitutions (Naidu et al., 2015).

All the treatments were applied until apparent refusal, reached after the number of strokes reported in Table 1. At the end of the brush application, all the specimens except the "ES" ones (cured as described in the following) were wrapped in a plastic film to avoid evaporation, then left to react for 48 hours in laboratory conditions and finally abundantly rinsed with water. After drying, the "3 M DAP" specimens were further treated by a limewater poultice for 24 hours (Franzoni et al., 2015a), then again rinsed with water and dried at room temperature. The "ES" specimens were left 
This is a post-peer-review, pre-copyedit version of the article: Sassoni E., Andreotti S., Scherer G.W., Franzoni E., Siegesmund S., Bowing of marble slabs: can the phenomenon be arrested and prevented by inorganic treatments?, Environmental Earth Sciences 77 (2018) 387. The final version is available online at DOI: 10.1007/s12665-018-7547-7

to react in laboratory conditions for 7 days, then a water poultice was applied for 4 days to complete the curing reactions of ethyl silicate, as described in detail in (Franzoni et al., 2015b).

\subsection{Characterization}

\subsubsection{Consolidation}

Before and after preliminary weathering, consolidation and thermal cycles, the dynamic elastic modulus $\left(E_{d}\right)$ of the specimens was determined, as reported in Fig. 2. $E_{d}$ was calculated according to the formula $E_{d}=\rho \cdot U P V^{2}$, where $\rho$ is the density and UPV is the ultrasonic pulse velocity. The UPV was measured across the $5 \mathrm{~cm}$ height of the cylinders and across the $2 \mathrm{~cm}$ thickness of the slabs, using a Geotron Elektronik instrument with $46 \mathrm{kHz}$ transducers, inserting a rubber couplant between the specimens and the transducers to improve the contact. $E_{d}$ was measured because it provides a quantitative and non-destructive evaluation of the conservation state of marble, since UPV and $E_{d}$ are highly sensitive to formation and closure of micro-cracks among grains (Köhler, 1988; Pamplona and Simon, 2012; Weiss et al., 2002).

The morphology of the new phases was determined by observation with a scanning electron microscope (Philips XL20 SEM), after coating the samples with aluminum to make them conductive.

The variations in total open porosity and pore size distribution caused by formation of the new phases were evaluated by mercury intrusion porosimetry (MIP), using a using a Fisons Macropore Unit 120 and Porosimeter 2000 Carlo Erba. Samples for MIP were obtained from the cylindrical specimens by chisel.

The composition of the new phases was determined by Fourier transform infrared spectroscopy (FT-IR) on powdered samples obtained from the cylinders. A Spectrum Two Perkin Elmer Spectrometer was used (ATR mode, 16 scans, range $4000-400 \mathrm{~cm}^{-1}$, resolution $1 \mathrm{~cm}^{-1}$ ).

\subsubsection{Dilatometry}

The residual strain after heating-cooling cycles was evaluated on pre-weathered and unweathered cylinders using a sophisticated dilatometer, able to test 6 specimens at a time and to work both in dry and wet conditions (Koch and Siegesmund, 2004). The thermal cycles were designed to resemble natural thermal excursions, so a maximum temperature of $90{ }^{\circ} \mathrm{C}$ was selected (Siegesmund et al., 2008). In fact, surface temperatures up to $80^{\circ} \mathrm{C}$ have been recorded for dark stones in hot climates (Bonazza et al., 2009). Each cycle was as follows: (i) holding at $20^{\circ} \mathrm{C}$ for $3 \mathrm{~h}$, to allow equilibration; (ii) heating from $20^{\circ} \mathrm{C}$ to $90^{\circ} \mathrm{C}$ at a rate of $1^{\circ} \mathrm{C} / \mathrm{min}$; (iii) holding at $90{ }^{\circ} \mathrm{C}$ for 6 $\mathrm{h}$; (iv) cooling from $90^{\circ} \mathrm{C}$ to $20^{\circ} \mathrm{C}$ at a rate of $1^{\circ} \mathrm{C} / \mathrm{min}$; (v) holding at $20^{\circ} \mathrm{C}$ for $3 \mathrm{~h}$. After running 4 dry cycles, the $E_{d}$ was measured as described above. Afterwards, 4 additional cycles were run in 
This is a post-peer-review, pre-copyedit version of the article: Sassoni E., Andreotti S., Scherer G.W., Franzoni E., Siegesmund S., Bowing of marble slabs: can the phenomenon be arrested and prevented by inorganic treatments?, Environmental Earth Sciences 77 (2018) 387. The final version is available online at DOI: 10.1007/s12665-018-7547-7

wet conditions, meaning that the specimens were immersed in deionized water during the heatingcooling cycles (performed as above). Because of water evaporation when the maximum temperature was reached, water was refilled at the end of each wet cycle. At the end of the 4 wet cycles, $E_{d}$ was measured again and then variations in open porosity and pore size distribution were evaluated by performing MIP on samples obtained from the specimens used for dilatometry.

\subsubsection{Bowing}

After consolidation, the slab tendency to bow was evaluated by subjecting specimens to thermal cycles (using the same apparatus adopted for preliminary bowing, Fig. 3a,b) and then determining the deviation from planarity by measuring the displacement in the middle of the slabs, as described above. To resemble realistic conditions (unlike the phase of preliminary weathering, $\S 2.3$ ), in this phase the maximum temperature was limited to $90{ }^{\circ} \mathrm{C}$ (Siegesmund et al., 2008). Each cycle consisted in heating to $90^{\circ} \mathrm{C}$ for $240 \mathrm{~min}$, then cooling for at least 5 hours (Fig. 3,d). After each cycle, the sample position was switched, so that after 6 cycles each sample had sat once in each position. In total, 12 cycles were performed on preliminarily bowed slabs (all the 7 conditions in Table 1) and 18 cycles on the unweathered slabs (untreated and treated by "1 M DAP"). At the end of the cycles, $E_{d}$ was measured again and compared to the initial condition.

\section{RESULTS AND DISCUSSION}

\subsection{Preliminary weathering}

Artificial weathering by heating at $200{ }^{\circ} \mathrm{C}$ for 1 hour reduced the $E_{d}$ of cylindrical specimens down to $31 \%$ ("verso") and 27\% ("contro") of the initial values (gray bars of pre-heated samples in Fig. 4b). This was a consequence of the opening of new cracks during heating, because of the anisotropic thermal behavior of calcite crystals (Siegesmund et al., 2000; Shushakova et al., 2013b). As a result, the response of unweathered and pre-weathered specimens to dilatometric tests was remarkably different, as illustrated in Fig. $4 \mathrm{a}$, where the residual strain after the thermal cycles is illustrated.

Unweathered cylinders exhibited a significant residual strain after 4 dry cycles, the first cycle causing the highest damage and the following three dry cycles only causing a minor increase in residual strain. This was expected, because of the so-called "buffering effect": micro-cracks formed during the first cycle allow some grain deformation during the following cycles, which leads to reduced stress, reduced formation of new micro-cracks and reduced additional residual strain after the thermal cycles (Ruedrich et al., 2002; Sassoni and Franzoni, 2014b; Sassoni et al., 2017). When 4 additional wet cycles were carried out, a significant further increase in residual strain was 
experienced. This points out the negative effect of the presence of moisture in the micro-cracks among grains, because water facilitates the growth of cracks between grains, by weakening the strained bonds at crack tips (Atkinson, 1984), and because water acts like a lubricant, thus making it easier for grains to slide with respect to each other (Koch and Siegesmund, 2004). Correspondingly, the unweathered specimens underwent a significant reduction in $E_{d}$ after the 4 dry cycles and a further decrease after the 4 wet ones (respectively, red and blue bars in Fig. 4b).

The pre-weathered specimens exhibited no significant residual strain after the 4 dry cycles, which again can be attributed to the "buffering effect" of the micro-cracks opened during the preliminary weathering (Sassoni and Franzoni, 2014b). Consistently, no further decrease in $E_{d}$ was experienced by pre-weathered specimens (red bars in Fig. 4b). After the additional 4 wet cycles, the specimens exhibited a negative residual strain, which can be attributed to a progressive collapse of the microstructure (Ruedrich et al., 2002). Correspondingly, during the wet cycles, specimens underwent some further (although limited) decrease in $E_{d}$ (blue bars in Fig. 4).

As for anisotropy, the two tested directions gave quite similar results, the "contro" direction generally experiencing a little more damage than the "verso" direction. The lack of remarkable anisotropy in Gioia Venato marble is in agreement with previous results (Siegesmund et al., 2008).

A comparison of bowing of not pre-bowed and pre-bowed slabs is reported in Fig. 4c,d. The prebowed slabs (which had already been subjected to 17 thermal cycles up to $120^{\circ} \mathrm{C}$ before the start of the cycles reported in Fig. 4) exhibited lower additional bowing in the "verso" direction and substantially the same bowing in the "contro" direction. Even if lower bowing would be reasonably expected for pre-bowed slabs (because progressive development of micro-cracks among grain is expected to reduce the effect of further heating-cooling cycles), the similar bowing registered in the "contro" direction is presumably owing to the fact that the level of bowing beyond which the bowing rate slows down had not been reached yet. In a previous study by Siegesmund et al. (2008) this level of bowing had been found to be $\sim 1 \mathrm{~mm} / \mathrm{m}$, hence the choice of limiting preliminary bowing to $1.1 \mathrm{~mm} / \mathrm{m}$ in the present study (cf. $\S 2.3$ ). However, it is possible that the level of bowing after which the bowing rate slows down was higher in the specific case of the marble tested here.

\subsection{Consolidation}

For each direction, the increase in $E_{d}$ after consolidation is reported in Fig. 5 for cylinders (a) and slabs (b) preliminarily subjected to artificial weathering.

In the case of cylinders, all the treatments were able to completely restore $E_{d}$ and, in the case of the "1 M DAP", "3 M DAP" and "ES" treatments, to even cause some improvement. The consolidating efficacy was increasing in the order "AmOx" < "EtOH" $\approx$ "IPA" $\approx$ "3 M DAP" < "ES" < "1 M DAP". The mechanical improvement was possible thanks to formation of new phases inside the micro-cracks formed during preliminary weathering. These new phases, visible in the SEM images reported in Fig. 
6 , improved the bonding among calcite grains, resulting in the measured increase in cohesion. As a consequence of formation of new phases, some reduction in the pore volume occurred (Fig. 7), but in no case did complete pore occlusion take place. The lack of complete pore occlusion is a positive feature, because otherwise the "buffering effect", made possible by the presence of voids among grains, would be impeded (Sassoni and Franzoni, 2014b), with possible worsening of the thermal behavior.

In terms of composition of the new phases (Fig. 8), the new bands in the FT-IR spectra of the "EtOH", "IPA", "1 M DAP" and "3 M DAP" treatments are compatible with HAP, although formation of octacalcium phosphate (OCP) cannot be excluded (Koutsopoulos, 2002). The presence of strong bands owing to calcite makes it difficult to conclusively identify the new phosphate phases; in particular, carbonated HAP might be formed after treatment, but the bands owing to carbonate groups in the HAP lattice might be covered by the bands owing to carbonate groups in the substrate. By combination of results obtained in this study by FT-IR with results obtained in previous studies by grazing incidence XRD and $\mu$-Raman spectrometry, it is likely that OCP was the main phase formed by the "EtOH" and "IPA" treatments (Sassoni et al., 2018a), whereas HAP and OCP are both formed in the case of the "1 M DAP" (Naidu and Scherer, 2014) and "3 M DAP" (Sassoni et al., 2015) treatments. The possible formation of OCP alongside (or even instead of) HAP is not expected to negatively affect the treatment effectiveness and durability, because OCP is much less soluble than calcite (although more soluble than HAP) (Naidu and Scherer, 2014). In the case of the other treatments, the FT-IR bands indicate formation of calcium oxalate monohydrate (whewellite) after the "AmOx" treatment (Conti et al., 2015) and silica after the "ES" treatment (Franzoni et al., 2015b).

In contrast to the cylinders, in the case of the slabs, only the "1 M DAP", "3 M DAP" and "ES" treatments were able to restore $E_{d}$ to the value before preliminary weathering, while the "EtOH", "IPA" and "AmOx" treatments caused some mechanical improvement but not complete $E_{d}$ restoration.

The fact that all treatments were more effective on the cylinders than on the slabs can be attributed, at least in part, to the different thicknesses of the two types of specimens (15 mm diameter in the case of cylinders, $20 \mathrm{~mm}$ thickness in the case of the slabs). The different effectiveness between the two types of specimens is particularly marked for the "EtOH" and "IPA" treatments, which have in common the addition of alcohol to the DAP solution. A possible reason for the reduction in the consolidating effectiveness for increasing thickness may be the volatility of the solution, responsible for a lower penetration depth of these two treatments. More detailed investigations will be carried out in future research to elucidate this point. A sensible reduction of the consolidating effectiveness was present also in the case of the "AmOx" treatment. This can be explained considering that the reaction between the ammonium phosphate solution and calcite is quick, which leads to a limited depth of whewellite formation (Osticioli et al., 2017). This reduced depth of whewellite formation could be enough to cause some mechanical improvement in the 
This is a post-peer-review, pre-copyedit version of the article: Sassoni E., Andreotti S., Scherer G.W., Franzoni E., Siegesmund S., Bowing of marble slabs: can the phenomenon be arrested and prevented by inorganic treatments?, Environmental Earth Sciences 77 (2018) 387. The final version is available online at DOI: 10.1007/s12665-018-7547-7

cylinders (15 mm diameter) but much less in the slabs (20 mm thickness). More tests are in progress to confirm this hypothesis.

\subsection{Arrest of bowing}

The consolidant's ability to limit the residual strain after thermal cycles was first investigated by dilatometry on pre-weathered specimens, with the results shown in Fig. 9. Whereas the untreated references (red curves) exhibited a negative residual strain, which is indicative of a collapse of the microstructure (Ruedrich et al., 2002), all the consolidated specimens exhibited zero or positive residual strain (with the exception of one of the "IPA" specimens). Because a negative residual strain indicates microstructure collapse, but a high positive residual strain indicates irreversible damage in the sample, the closer the residual strain is to zero, the better. Notably, all the HAP-based treatments (with the exception of one of the "IPA" specimens) gave residual strain values very close to zero, which indicates little or no damage. In contrast, specimens treated by "ES" and especially by "AmOx" exhibited very high residual strain, particularly after the 4 wet cycles. This is an indication that severe damage occurred in these samples after the thermal cycles.

Correspondingly, in terms of dynamic elastic modulus $E_{d}$, after the cycles the "ES" and "AmOx" specimens basically lost all the benefit derived from consolidation. This is indicated by $E_{d}$ decreasing back to the level before consolidation (actually, at the end of the tests the "AmOx" specimens exhibited $E_{d}$ even lower than the untreated specimens) (Fig. 9c,d). Although $E_{d}$ decreased after the dry cycles and especially after the wet cycles, at the end of the tests the HAP-treated samples still had higher $E_{d}$ than the untreated reference (Fig. 9c,d). The magnitude of the benefit was higher for treatments involving more concentrated DAP solutions. However, because some decrease in $E_{d}$ occurred also in the HAP-treated specimens, further tests should be carried out in the future to ascertain the behavior of the HAP-treated samples after a higher number of thermal cycles.

The results of the bowing tests on pre-bowed slabs (Fig. 10) are in good agreement with those of the dilatometric tests.

First, it is immediately evident that the "AmOx" specimens experienced much higher bowing than all the other specimens, even the untreated references. After 12 cycles, the "AmOx" samples reached a value of bowing that is more than 3 times that of the untreated references (Fig. 10c,d).

Consistently, at the end of the bowing cycles the $E_{d}$ of the "AmOx" slabs is definitely lower than that of the untreated references (Fig. 10e,f). Such a behavior of the "AmOx" specimens is quite unexpected: the "AmOx" treatment is known to generally reach quite low penetration depth (because of the speed of the reaction between calcite and the ammonium oxalate solution) (Osticioli et al., 2017) and consequent modest efficacy (Sassoni et al., 2015), but in turn it is expected to cause limited alteration in pore size distribution. This latter feature is positive, because it ensures that the "buffering effect" (allowed by voids among grains) is not inhibited after consolidation. Nonetheless, 
MIP revealed that the dilatometric cycles caused a big increase in open porosity in the "AmOx" samples (Fig. 7), which is consistent with the dilatometric and bowing results, but still unexpected. Several possible explanations for the damage observed in the "AmOx" samples after the thermal cycles (in terms of porosity increase, residual strain and bowing) might exist. First, the mineral formed by the "AmOx" treatment (i.e. calcium oxalate monohydrate or whewellite) might have a significantly different thermal expansion coefficient, compared to calcite, which might result in stress generation upon temperature variations. However, no data were found in the literature about whewellite thermal expansion coefficient to confirm this hypothesis. A second reason might be the stability of whewellite as the temperature increases. Whewellite is known to transform into anhydrous calcium oxalate at $162{ }^{\circ} \mathrm{C}$ (Frost and Weier, 2004), well beyond the maximum temperature reached during the cycles $\left(90^{\circ} \mathrm{C}\right)$. However, investigations by high temperature X-ray diffraction camera have pointed out that an intermediate phase (not better identified) starts to form at $90^{\circ} \mathrm{C}$ (Wiedemann and Bayer, 1988). The formation of this new phase, possibly in combination with the presence of water inside the microcracks, might have resulted in stress among the grains. A third possible explanation is that whewellite formed inside the micro-cracks is very stiff, so that (even if grains are not completely occluded) deformation of calcite grains upon temperature variations is impeded, which results in stress. However, to confirm any of these hypotheses specific experimental tests, beyond the scope of this study, are necessary and will be carried out in future research.

In the case of the "ES" samples, differently from the dilatometric results, at the end of the bowing cycles the remaining $E_{d}$ was higher than that of the untreated references (Fig. 10e,f), which suggests that "ES" was able to mitigate the effect of the thermal cycles. Consistently, the measured bowing was lower ("contro") or only slightly higher ("verso") than the reference (Fig. 10c,d).

For all the HAP-treatment formulations, in agreement with dilatometric results, bowing was lower than (or very close to) that of the untreated reference (Fig. 10a-d), meaning that the treatments provided some protection against thermal weathering (or, at least, did not cause any worsening of the thermal behavior). The "EtOH" and "IPA" specimens exhibited a distinct but consistent behavior. Initially, all the samples underwent some concave bowing; then, during the prosecution of the test, they exhibited a slight, constant bowing increase in the convex direction, like the other specimens (Fig. 10a,b). This resulted in the final bowing of "EtOH" and "IPA" specimens being slightly negative or very close to zero after 12 cycles (Fig. 10c,d). The "1 M DAP" and, to a higher extent, the "3 M DAP" treatments caused bowing similar to the untreated reference (Fig. 10a-d), but still much higher residual $E_{d}$ after 12 cycles (Fig. 10e,f). A possible explanation for the different behavior of the specimens treated by "EtOH" and "IPA", on the one hand, and by "1 M DAP" and "3 M DAP", on the other hand, might be the different stiffness of the new phases formed in the two cases (respectively, OCP (Sassoni et al., 2018a) and HAP+OCP (Naidu and Scherer, 2014; Sassoni et al., 2015)). The more compliant the new phases formed after treatment, the more deformation of calcite grains upon heating can be accommodated without causing stress at the grain boundaries. HAP has quite high 
This is a post-peer-review, pre-copyedit version of the article: Sassoni E., Andreotti S., Scherer G.W., Franzoni E., Siegesmund S., Bowing of marble slabs: can the phenomenon be arrested and prevented by inorganic treatments?, Environmental Earth Sciences 77 (2018) 387. The final version is available online at DOI: 10.1007/s12665-018-7547-7

stiffness ( 150 GPa, based on calculations by Zhang and Tamilselvan (2007)), while no values were found in the literature for OCP. In case OCP is sensibly less stiff than HAP, this may account for the different thermal behavior registered for specimens treated by the different treatments; the shape and orientation of the grains might also play an important role. To validate this hypothesis, specific tests are needed and will be carried out in future research.

Compared to "ES", the HAP-treatments showed clear advantages in terms of residual strain and residual $E_{d}$ after the dilatometric tests on cylinders (Fig. 9), even though the final bowing and the corresponding residual $E_{d}$ in the slabs were similar (Fig. 10). Although not specifically measured in the present study, a further important advantage of the HAP-treatments, compared to "ES", is their much better aesthetic compatibility when applied to marble: whereas all the tested formulations of the HAP-treatment have proven to cause color changes below the detection limit by the human eye (Sassoni et al., 2015; Sassoni et al., 2018a), the "ES" treatment has been reported to cause significant darkening in marble, exceeding the threshold of color change commonly considered as acceptable after conservation works (Sassoni et al., 2015).

\subsection{Prevention of bowing}

The results of dilatometric tests on unweathered specimens are reported in Fig. 11.

In both directions, the HAP-treatments exhibited residual strain after the dilatometric tests lower than the untreated reference (Fig. 11a,b) and, consistently, the final $E_{d}$ was always higher than the reference (Fig. 11c,d). Similarly to the case of pre-heated specimens, the "3 M DAP" treatment caused the lowest residual strain after 4 dry and 4 wet cycles (Fig. 11a,b) and accordingly the highest final $E_{d}$ (Fig. $\left.11 \mathrm{c}, \mathrm{d}\right)$. This is in agreement also with previous results obtained on this formulation, which exhibited a very good ability to mitigate thermal damage (Sassoni et al., 2017). Again, similarly to the case of pre-weathered specimens, also in the case of the unweathered samples the "AmOx" treatment caused the highest residual strain at the end of the thermal cycles, also compared to the untreated references (Fig. 11a,b). Accordingly, any mechanical benefit achieved after consolidation was basically lost after the thermal cycles (Fig. 11c,d). In the case of the "ES" specimens, in spite of the initial benefit right after consolidation, the residual strain at the end of the dilatometric cycles was basically the same as the untreated reference (Fig. 11a,b) and any mechanical benefit was lost (Fig. $11 \mathrm{c}, \mathrm{d})$.

To evaluate the possibility of preventing bowing, only 1 treatment had to be selected because of limitations in the number of specimens that could be tested at a time. As mentioned in $\S 2.4$, the "1 M DAP" treatment was selected as it provided the highest $E_{d}$ increase right after consolidation (green bars in Fig. $11 \mathrm{c}, \mathrm{d}$ ) - even though the "3 M DAP" treatment later provided the highest $E_{d}$ retained after the thermal cycles (blue bars in Fig. 11c,d). Comparing results of dilatometric tests on untreated and "1 M DAP"-treated specimens, it is possible to observe that, at the end of the cycles, the HAP-treated 
specimens exhibited lower residual strain and slightly higher $E_{d}$ than the untreated reference (Fig. 12a,b). Correspondingly, after 18 bowing cycles, the treated slabs exhibited lower bowing than the untreated ones, in both directions (Fig. 12a-d). Correspondingly, compared to the untreated specimens, the treated ones exhibited higher residual $E_{d}$ after 18 cycles (Fig. 12e,f). It is noteworthy that all the decrease in $E_{d}$ caused by the thermal cycles had already been experienced after the first 12 cycles.

\section{CONCLUSIONS}

Based on the obtained results, the following conclusions can be derived:

1) With the aim of arresting bowing, all the HAP-treatments exhibited promising results. The residual strain and the bowing were lower or equal to those of untreated marble, while the residual dynamic elastic modulus $\left(E_{d}\right)$ after the thermal cycles was always higher in the consolidated specimens than in the untreated references. The magnitude of the benefit actually depended on the specific formulation of the HAP-treatment: the formulations involving $\mathrm{EtOH}$ and IPA caused lower bowing but also lower $E_{d}$ at the end of the thermal cycles; the formulations involving higher DAP concentrations ("1 M DAP" and "3 M DAP") exhibited final bowing slightly lower or similar to the untreated references, but still sensibly higher residual $E_{d .}$. The "AmOx" treatment exhibited the worst behavior among all the investigated consolidants, the residual strain and the bowing always resulting the highest and exceeding by far the unconsolidated references. The "ES" treatment gave good results in terms of bowing and residual $E_{d}$ after the bowing cycles, but still all the benefit deriving from consolidation was lost after the dilatometric tests (showing higher residual strain and similar residual $E_{d}$ for "ES" and untreated specimens).

2) With the aim of preventing bowing, unweathered specimens subjected to dilatometric tests gave results in agreement with those of pre-weathered specimens. "AmOx" caused higher residual strain and basically no advantage in terms of $E_{d}$, compared to the untreated reference. "ES" specimens lost all the benefit deriving from consolidation, once subjected to the thermal cycles. The HAP-treatments gave the most encouraging results, the lowest residual strain and the highest residual $E_{d}$ being obtained for the "1 M DAP" and "3 M DAP" specimens. The former formulation, exhibiting the highest efficacy after consolidation and a good residual $E_{d}$ after the thermal cycles, was selected for application on unweathered slabs, to evaluate the treatment ability to prevent bowing. After 18 cycles, the treated slabs experienced lower bowing and higher residual $E_{d}$, thus indicating that some mitigation of thermal weathering can be achieved by preliminary treatment of marble slabs with the investigated treatment.

All things considered, the findings of the present study suggest that conservation treatments able to strengthen marble without causing excessive pore occlusion and stiffening are likely to be preferable, in the view of achieving improved durability to thermal cycles. In any case, the evaluation 
of marble thermal behavior after treatment is confirmed as a parameter of fundamental importance to assess the suitability of any conservation treatment. Indeed, depending on the treatment properties, all the mechanical benefit derived from consolidation might be lost after a few thermal cycles, which makes the conservation treatment useless or in some cases even counterproductive.

\section{ACKNOWLEDGMENTS}

This project has received funding from the European Union's Horizon 2020 research and innovation programme under the Marie Sklodowska-Curie grant agreement No 655239 (HAP4MARBLE project, "Multi-functionalization of hydroxyapatite for restoration and preventive conservation of marble artworks"). Johanna Menningen and Christian Knell (University of Göttingen) are gratefully acknowledged for their help in setting up the dilatometric and bowing tests.

\section{REFERENCES}

Atkinson BK (1984) Subcritical crack growth in geological materials. J Geophys Res 89:4077-4114, DOI: 10.1029/JB089iB06p04077

Bonazza A, Sabbioni C, Messina P, Guaraldi C, De Nuntiis P (2009) Climate change impact: Mapping thermal stress on Carrara marble in Europe. Sci Total Environ 407:4506-4512. DOI: 10.1016/j.scitotenv.2009.04.008

Conti C, Casati M, Colombo C, Possenti P, Realini M, Gatta GD, Merlini M, Brambilla L, Zerbi G (2015) Synthesis of calcium oxalate trihydrate: New data by vibrational spectroscopy and synchrotron X-ray diffraction. Spectrochim Acta A 150:721-730. DOI: 10.1016/j.saa.2015.06.009

European Standard EN 16306 (2013) Natural stone test methods - Determination of resistance of marble to thermal and moisture cycles

Franzoni E, Graziani G, Sassoni E (2015b) TEOS-based treatments for stone consolidation: acceleration of hydrolysis-condensation reactions by poulticing. J Sol-Gel Sci Techn 74:398-405. DOI: 10.1007/s10971-014-3610-3

Franzoni E, Sassoni E, Graziani G (2015a) Brushing, poultice or immersion? Role of the application technique on the performance of a novel hydroxyapatite-based consolidating treatment for limestone. J Cult Herit 16:173-184. DOI: 10.1016/j.culher.2014.05.009

Frost RL, Weier ML (2004) Thermal treatment of whewellite - A thermal analysis and Raman spectroscopic study, Thermochim Acta 409:79-85. DOI: 10.1016/S0040-6031(03)00332-0

Graziani G, Sassoni E, Franzoni E, Scherer GW (2016) Hydroxyapatite coatings for marble protection: Optimization of calcite covering and acid resistance. Appl Surf Sci 368:241-257. DOI: 10.1016/j.apsusc.2016.01.202 
Graziani G, Sassoni E, Scherer GW, Franzoni E (2017) Penetration depth and redistribution of an aqueous ammonium phosphate solution used for porous limestone consolidation by brushing and immersion. Constr Build Mat 148:571-578. DOI: 10.1016/j.conbuildmat.2017.05.097

Grimm WD (1999) Beobachtungen und Überlegungen zur Verformung von Marmorobjekten durch Gefügeauflockerung. Zeitschrift der Deutschen Geologischen Gesellschaft 150/2, 195-236 [in German]

Jornet A, Teruzzi T, Rück P (2002) Bowing of Carrara marble slabs: comparison between natural and artificial weathering. In: Prikryl R, Viles HA, Understanding and managing of stone decay (SWAPNET 2001), Karolinum Press, Prague, 161-170

Kieslinger A (1934) Gesteinskundliche Untersuchungen an alten Grabsteinen. Geologie und Bauwesen 6:1-21 [in German]

Koch A. (2006) Deformation von Fassadenplatten aus Marmor, Universitätsverlag Göttingen, Ph.D. Thesis [in German]

Koch A, Siegesmund S (2004) The combined effect of moisture and temperature on the anomalous expansion behaviour of marble. Environ Geol 46:350-363. DOI: 10.1007/s00254-004-1037-9

Köhler W (1988) Preservation problems of Carrara Marble sculptures in Potsdam Sanssouci ("Radial structural destruction of Carrara Marble"). In: Proceedings of the 6th International Congress on Deterioration and Conservation of Stone, Torun, 653-662.

Koutsopoulos S (2002) Synthesis and characterization of hydroxyapatite crystals: A review study on the analytical methods. J Biomed Mater Res 15:600-612, DOI: 10.1002/jbm.10280

Logan JM, Hadedt M, Lehnert D, Denton M (1993) A case study of the properties of marble as building veneer. Int J Rock Mech Min 30:1531-1537. DOI: 10.1016/0148-9062(93)90152-4

Logan JM (2004) Laboratory and case studies of thermal cycling and stored strain on the stability of selected marbles. Environ Geol 46:456-467. DOI: 10.1007/s00254-004-1047-7

Liu Q, Zhang B (2011) Synthesis and characterization of a novel biomaterial for the conservation of historic stone building and sculptures. Mater Sci Forum 675-677:317-320

Ma X, Balonis M, Pasco H, Toumazou M, Counts D, Kakoulli I (2017) Evaluation of hydroxyapatite effects for the consolidation of a Hellenistic-Roman rock-cut chamber tomb at Athienou-Malloura in Cyprus. Constr Build Mater 150:333-344. DOI: 10.1016/j.conbuildmat.2017.06.012

Malaga K, Schouenborg B, Alnaes L, Bellopede R, Brundin JA (2004) Field exposure sites and accelerated laboratory test of marble panels. In: Prikryl (Ed) Dimension stone, Proceedings of the international conference on dimension stone, 14-17 June 2004, Prague (CZ), 261-266

Malaga-Starzec K, Åkesson U, Lindqvist JE, Schouenborg B (2006) Microscopic and macroscopic characterization of the porosity of marble as a function of temperature and impregnation. Constr Build Mater 20:939-947. DOI: 10.1016/j.conbuildmat.2005.06.016

Malaga-Starzec K, Lindqvist JE, Schouenborg B (2002) Experimental study on the variation in porosity of marble as a function of temperature. In: Siegesmund S, Weiss T, Vollbrecht A (Eds) 
Natural stone, weathering phenomena, conservation strategies and case studies, Geological Society, London, Special Publications 205:81-88. DOI: 10.1144/GSL.SP.2002.205.01.07

Marini P, Bellopede R (2009) Bowing of marble slabs: evolution and correlation with mechanical decay. Constr Build Mater 23:2599-2605. DOI: 10.1016/j.conbuildmat.2009.02.010

Matteini M, Rescic S, Fratini F, Botticelli G (2011) Ammonium phosphates as consolidating agents for carbonatic stone materials used in architecture and cultural heritage: Preliminary research. Int $\mathrm{J}$ Archit Herit 5:717-736. DOI: 10.1080/15583058.2010.495445

Molina E, Rueda-Quero L, Benavente D, Burgos-Cara A, Ruiz-Agudo E, Cultrone G (2017) Gypsum crust as a source of calcium for the consolidation of carbonate stones using a calcium phosphatebased consolidant, Constr Build Mater 143:298-311. DOI: 10.1016/j.conbuildmat.2017.03.155

Naidu S, Blair J, Scherer GW (2016) Acid-resistant coatings on marble. J Am Ceram Soc 99:34213428. DOI: $10.1111 /$ jace. 14355

Naidu S, Liu C, Scherer GW (2015) Hydroxyapatite-based consolidant and the acceleration of hydrolysis of silicate-based consolidants. J. Cult. Herit. 16:94-101. DOI: 10.1016/j.culher.2014.01.001.

Naidu S, Sassoni E, Scherer GW (2011) New treatment for corrosion-resistant coatings for marble and consolidation of limestone. In: Stefanaggi M, Vergès-Belmin V (Eds), "Jardins de Pierres Conservation of stone in Parks, Gardens and Cemeteries", Paris (F) 22-24 June 2011, 289-294

Naidu S, Scherer GW (2014) Nucleation, growth and evolution of calcium phosphate films on calcite. J Colloid Interf Sci 435:128-137. DOI: 10.1016/j.jcis.2014.08.018

Osticioli I, Botticelli G, Matteini P, Siano S, Pini R, Matteini M (2017) Micro-Raman analysis on the combined use of ammonium oxalate and ammonium phosphate for the consolidation and protection of carbonate stone artifacts. J Raman Spectrosc 48:966-971. DOI: 10.1002/jrs.5150

Pamplona M, Simon S (2012) Ultrasonic pulse velocity - A tool for the condition assessment of outdoor marble sculptures, Proceedings of 12th International Congress on Deterioration and Conservation of Stone, New York City (USA), $22-26$ October 2012, 1-13, http://iscs.icomos.org/pdffiles/NewYorkConf/pampsimo.pdf

Possenti E, Colombo C, Bersani D, Bertasa M, Botteon A, Conti C, Lottici PP, Realini M (2016) New insight on the interaction of diammonium hydrogenphosphate conservation treatment with carbonatic substrates: A multi-analytical approach. Microchem J 127:79-86. DOI: 10.1016/j.microc.2016.02.008

Rayleigh (1934) The Bending of Marble, Proceedings of the Royal Society of London. Series A, Containing Papers of a Mathematical and Physical Character, 144:266-279. http://www.jstor.org/stable/2935557

Royer-Carfagni G (1999) Some considerations on the warping of marble façades: the example of Alvar Aalto's Finland Hall In Helsinki. Const Build Mater 13:449-457. DOI: 10.1016/S09500618(99)00036-7 
Ruedrich J, Weiss T, Siegesmund S (2002) Thermal behavior of weathered and consolidated marbles. In: Siegesmund S, Weiss T, Vollbrecht A (Eds) Natural stone, weathering phenomena, conservation strategies and case studies, Geological Society, London, Special Publications 205:255-271. DOI: 10.1144/GSL.SP.2002.205.01.19

Sassoni E (2017) Phosphate-based treatments for conservation of stone. RILEM Technical Letters 2:14-19. DOI: $10.21809 /$ rilemtechlett.2017.34

Sassoni E, Franzoni E (2014a) Sugaring marble in the Monumental Cemetery in Bologna (Italy): characterization of naturally and artificially weathered samples and first results of consolidation by hydroxyapatite. Appl Phys A-Mater 117:1893-1906. DOI: 10.1007/s00339-014-8629-3

Sassoni E, Franzoni E (2014b) Influence of porosity on artificial deterioration of marble and limestone by heating. Appl Phys A-Mater 115:809-816. DOI: 10.1007/s00339-013-7863-4

Sassoni E, Graziani G, Franzoni E (2015) Repair of sugaring marble by ammonium phosphate: comparison with ethyl silicate and ammonium oxalate and pilot application to historic artifact. Mater Design 88:1145-1157. DOI: 10.1016/j.matdes.2015.09.101

Sassoni E, Graziani G, Ridolfi G, Bignozzi MC, Franzoni E (2017) Thermal behavior of Carrara marble after consolidation by ammonium phosphate, ammonium oxalate and ethyl silicate. Mater Design 120:345-353. DOI: 10.1016/j.matdes.2017.02.040

Sassoni E, Graziani G, Franzoni E, Scherer GW (2018a) Calcium phosphate coatings for marble conservation: influence of ethanol and isopropanol addition to the precipitation medium on the coating microstructure and performance. Corros Sci 136:255-267, DOI: 10.1016/j.corsci.2018.03.019

Sassoni E, Graziani G, Franzoni E, Scherer GW (2018b) New method for controllable accelerated aging of marble: use for testing of consolidants. J Am Ceram Soc, DOI: 10.1111/jace.15522

Sassoni E, Naidu S, Scherer GW (2011) The use of hydroxyapatite as a new inorganic consolidant for damaged carbonate stones. J Cult Herit 12:346-355. DOI: 10.1016/j.culher.2011.02.005

Siegesmund S, Ruedrich J, Koch A (2008) Marble bowing: comparative studies of three different public building facades. Environ Geol 56:473-494. DOI: 10.1007/s00254-008-1307-z

Siegesmund S, Ullemeyer K, Weiss T, Tschegg EK (2000) Physical weathering of marbles caused by anisotropic thermal expansion. Int J Earth Sci 89:170-182. DOI: 10.1007/s005310050324

Siegesmund S, Weiss T, Vollbrecht T, Ullemeyer K (1999) Marble as a natural building stone: rock fabrics, physical and mechanical properties, Zeitschrift der Deutschen Geologischen Gesellschaft Band 150 Heft 2, 237-257

Shushakova V, Fuller Jr. ER, Heidelbach F, Mainprice D, Siegesmund S (2013a) Marble decay induced by thermal strains: Simulations and experiments. Environ Earth Sci 69:1281-1297. DOI: $10.1007 / \mathrm{s} 12665-013-2406-z$

Shushakova V, Fuller Jr. ER, Siegesmund S (2013b) Microcracking in calcite and dolomite marble: Microstructural influences and effects on properties. Environ Earth Sci 69:1263-1279. DOI: 10.1007/s12665-012-1995-2 
TEAM project (2005) Technical Final Report, available at http://buildingteam.extweb.sp.se/PDF/ TEAM\%20Final\%20Report.pdf

Weiss T, Rasolofosaon PNJ, Siegesmund S (2002) Ultrasonic wave velocities as a diagnostic tool for the quality assessment of marble, In: Siegesmund S, Weiss T, Vollbrecht A (Eds), Natural stone, weathering phenomena, conservation strategies and case studies. Geological Society Special Publications, London, UK, 205:149-164, DOI: 10.1144/GSL.SP.2002.205.01.12

Weiss T, Siegesmund S, Fuller Jr, ER (2003) Thermal degradation of marble: Indications from finiteelement modelling. Build Environ 38:1251-1260. DOI: 10.1016/S0360-1323(03)00082-9

Wiedemann G, Bayer G (1988) Kinetics of the formation of whewellite and weddelite by displacement reactions. J Thermal Anal 33:707- 718. DOI: 10.1007/BF02138577

Yang F, Liu Y (2014) Artificial hydroxyapatite film for the conservation of outdoor marble artworks, Materials Letters 124:201-203. DOI: 10.1016/j.matlet.2014.03.081

Yang F, Zhang B, Liu Y, Guofeng W, Zhang H, Cheng W, Xu Z (2011) Biomimic conservation of weathered calcareous stones by apatite. New $J$ Chem 35:887-892. DOI: $10.1039 / \mathrm{CONJ} 00783 \mathrm{H}$

Zhang D, Tamilselvan A (2007) Lattice energy and mechanical stiffness of hydroxyapatite. J Mater Sci: Mater Med 18:79-87. DOI 10.1007/s10856-006-0665-x 

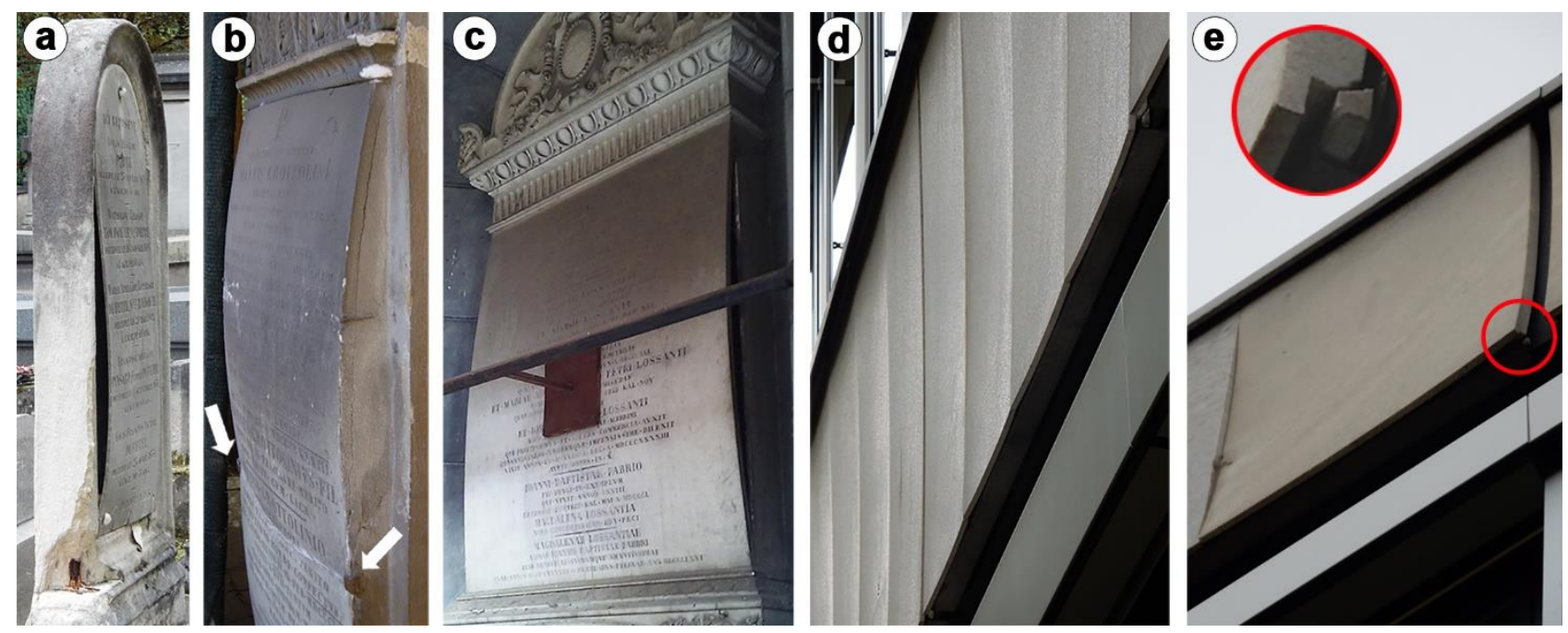

Fig. 1 Examples of bowed marble slabs: (a) Père Lachaise cemetery in Paris, France (XIX cent.); (b,c) Monumental Cemetery in Bologna, Italy (XIX cent.); (d,e) "Theologicum" building in the Göttingen University campus, Germany (XX cent.). In (b), metal braces (pointed by white arrows) were introduced to contrast bowing and mortar was used to fill the void between the slab and the supporting wall; however, because bowing proceeded after brace insertion, the slab fractured right where the braces had been placed. In (c), an external support was introduced to arrest bowing, with the risk of slab fracturing. In (e), the slab on the extreme left was substituted, which reveals the level of bowing of the adjacent, central slab; in the inset, a detail of the fractured edge (serving as support) is shown. 
This is a post-peer-review, pre-copyedit version of the article: Sassoni E., Andreotti S., Scherer G.W., Franzoni E., Siegesmund S., Bowing of marble slabs: can the phenomenon be arrested and prevented by inorganic treatments?, Environmental Earth Sciences 77 (2018) 387. The final version is available online at DOI: 10.1007/s12665-018-7547-7

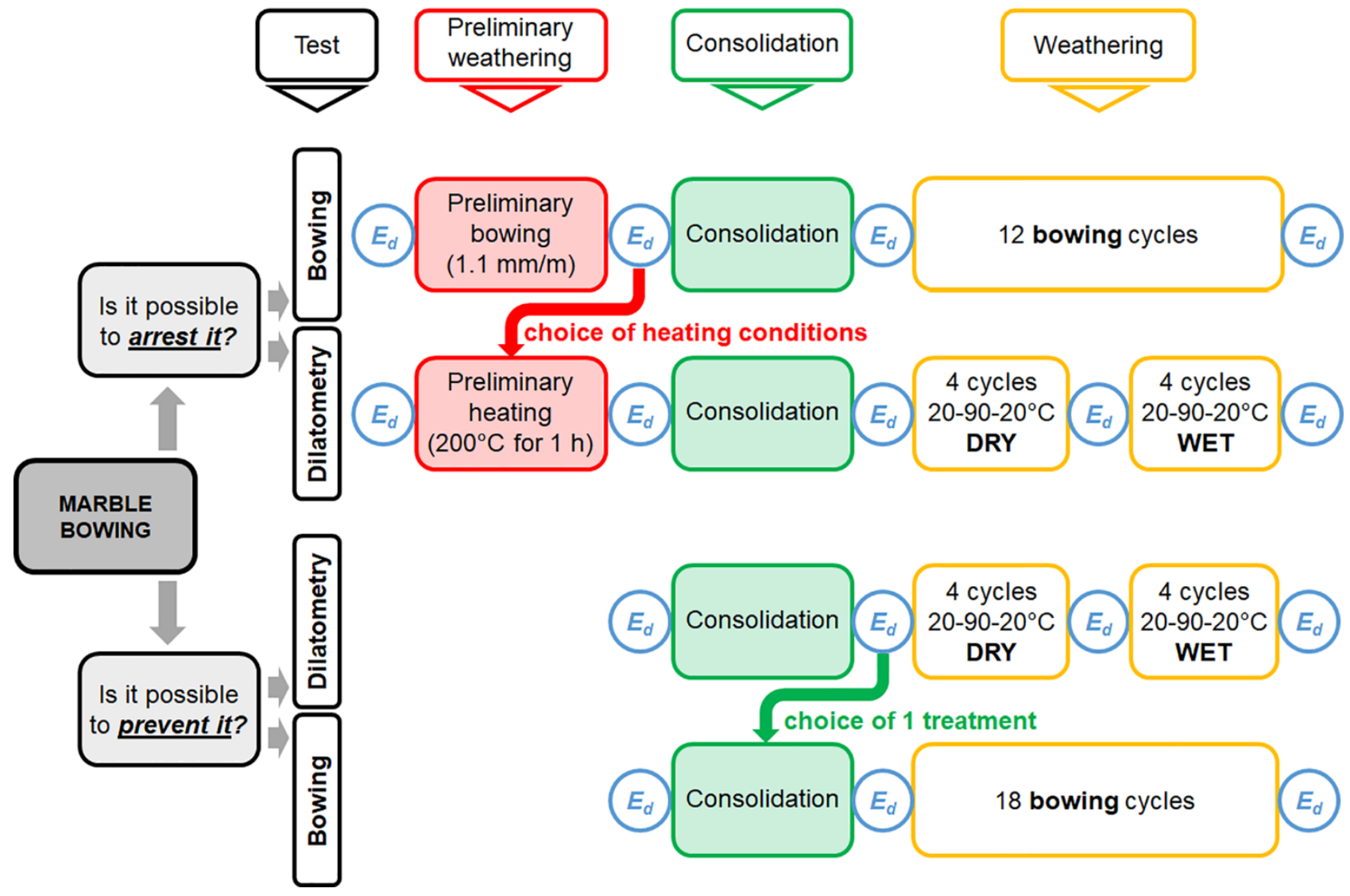

Fig. 2 Outline of the study ( $E_{d}=$ dynamic elastic modulus, assessed by ultrasonic measurement). 

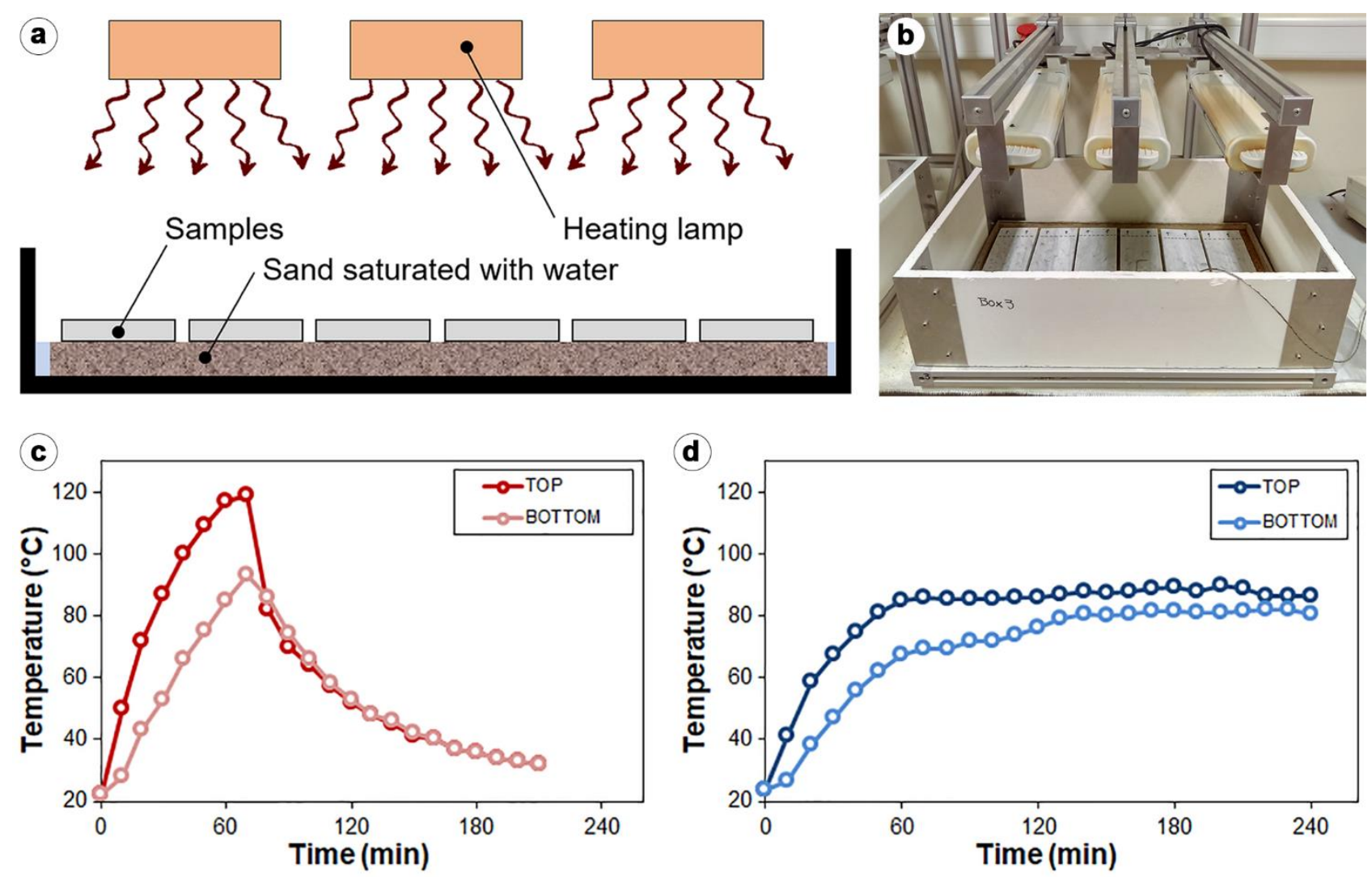

Fig. 3 Experimental set-up used for the bowing tests and measured temperature vs time diagrams: (a) scheme and (b) photo illustrating the set-up (lamps provide heat to the upper side of the samples, while the lower side is sitting on a sand bath saturated with water); (c) temperature vs time diagram during the thermal cycles for inducing preliminary bowing (heating up to $120^{\circ} \mathrm{C}$ for $70 \mathrm{~min}$, unrealistic accelerated conditions); (d) temperature vs time diagram during the thermal cycles for evaluating the actual ability to resist bowing (heating up to $90{ }^{\circ} \mathrm{C}$ for $240 \mathrm{~min}$, more realistic conditions). The temperature of the samples was measured in the upper side facing the lamps ("Top") and in the lower side in contact with water ("Bottom") using an infrared gun. 

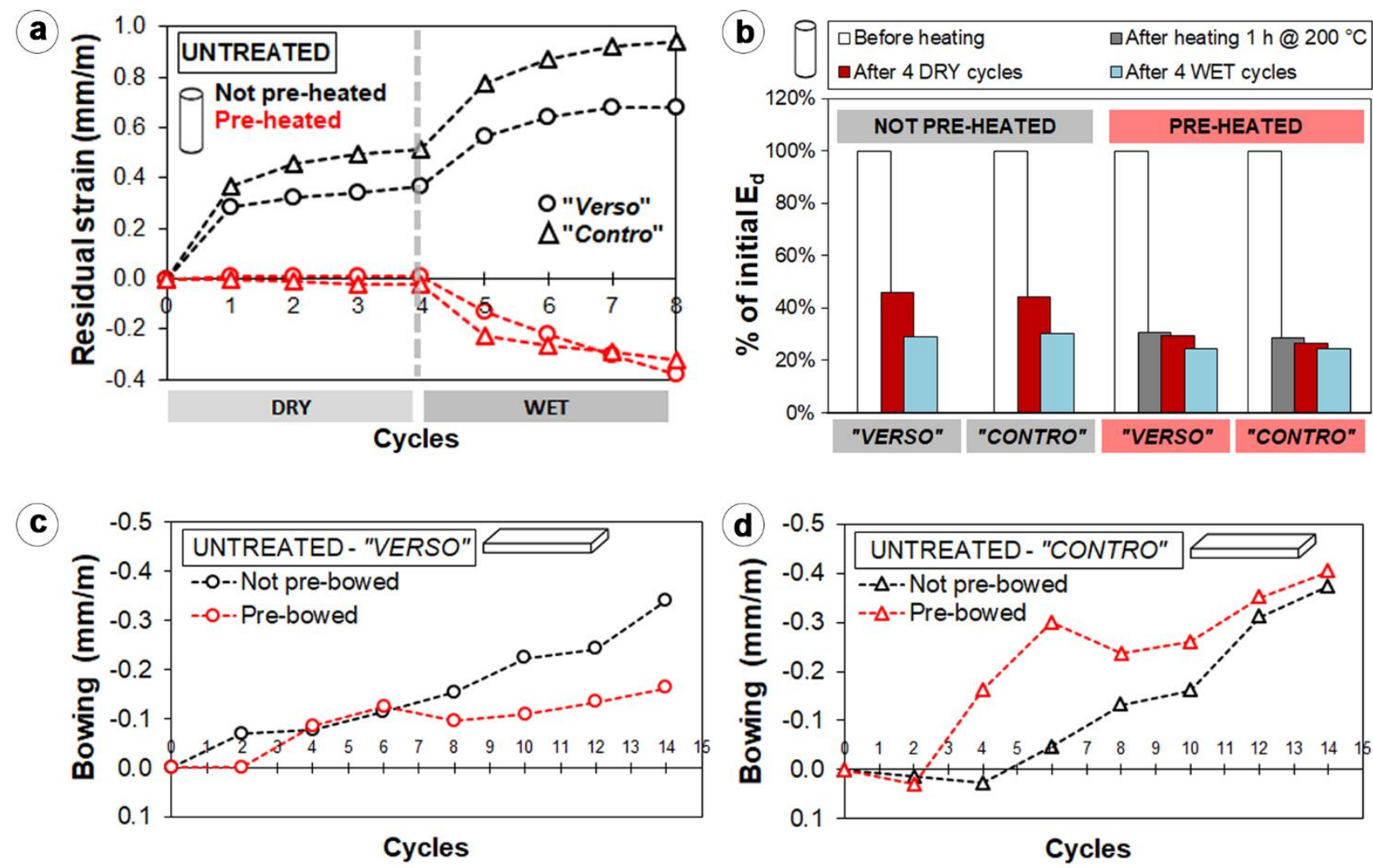

Fig. 4 Results of dilatometric and bowing tests on untreated specimens, not pre-heated (black curves) and pre-heated (red curves): (a) residual strain and (b) $E_{d}$ variation after dilatometric cycles; (c,d) bowing in the "verso" (circles) and "contro" (triangles) directions.
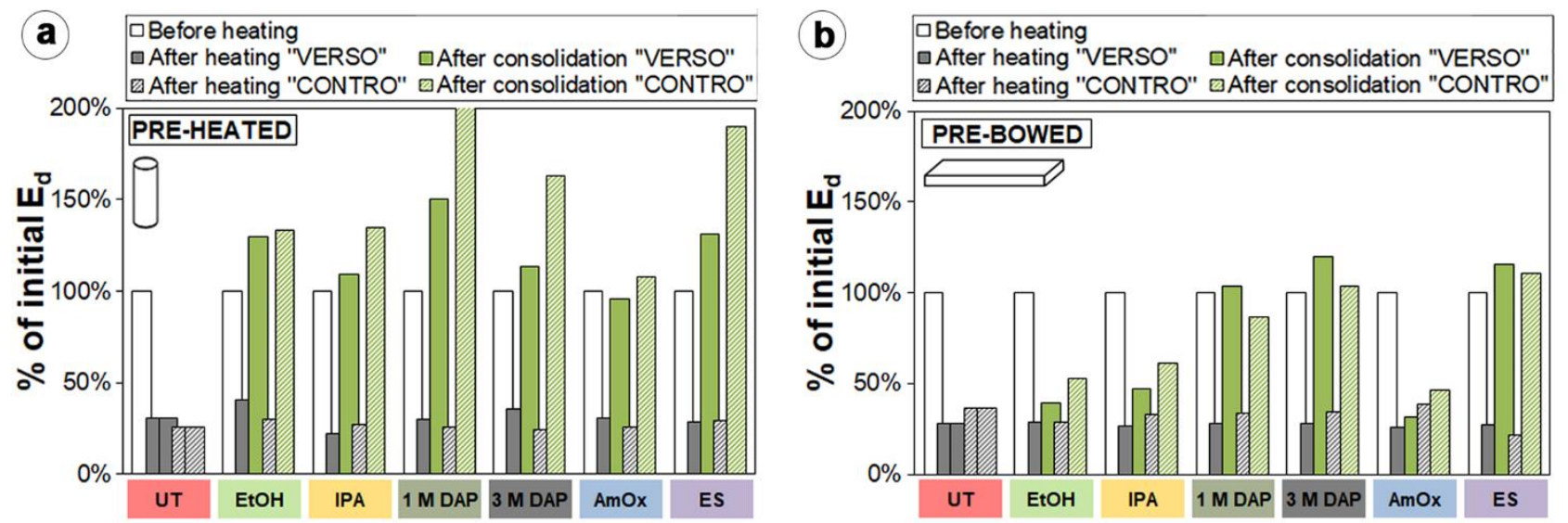

Fig. $5 E_{d}$ increase after consolidation in cylinders (a) and slabs (b) preliminarily artificially weathered. 
This is a post-peer-review, pre-copyedit version of the article: Sassoni E., Andreotti S., Scherer G.W., Franzoni E., Siegesmund S., Bowing of marble slabs: can the phenomenon be arrested and prevented by inorganic treatments?, Environmental Earth Sciences 77 (2018) 387. The final version is available online at DOI: 10.1007/s12665-018-7547-7
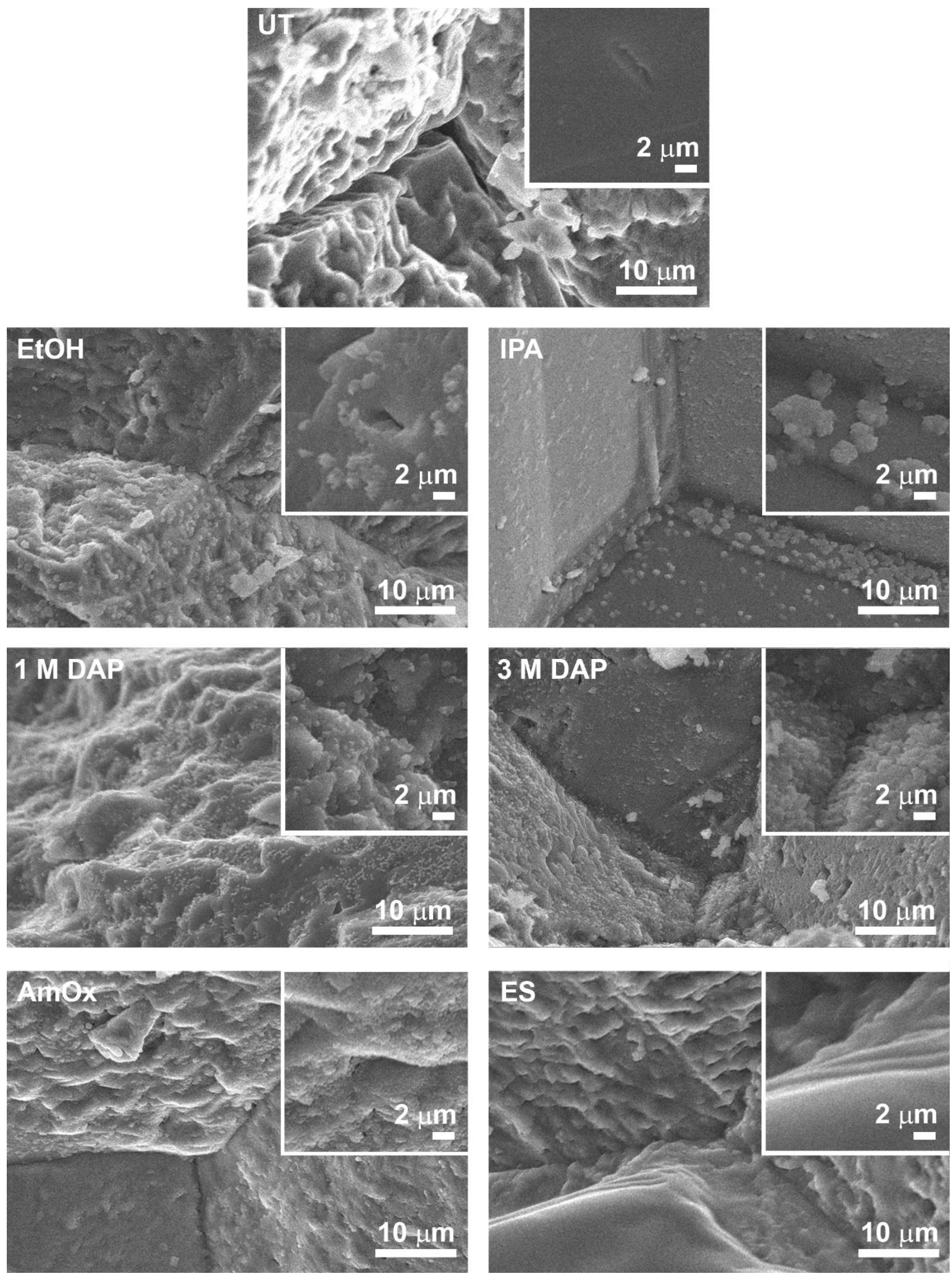

Fig. 6 SEM images of pre-weathered untreated and treated samples. 
This is a post-peer-review, pre-copyedit version of the article: Sassoni E., Andreotti S., Scherer G.W., Franzoni E., Siegesmund S., Bowing of marble slabs: can the phenomenon be arrested and prevented by inorganic treatments?, Environmental Earth Sciences 77 (2018) 387. The final version is available online at DOI: 10.1007/s12665-018-7547-7
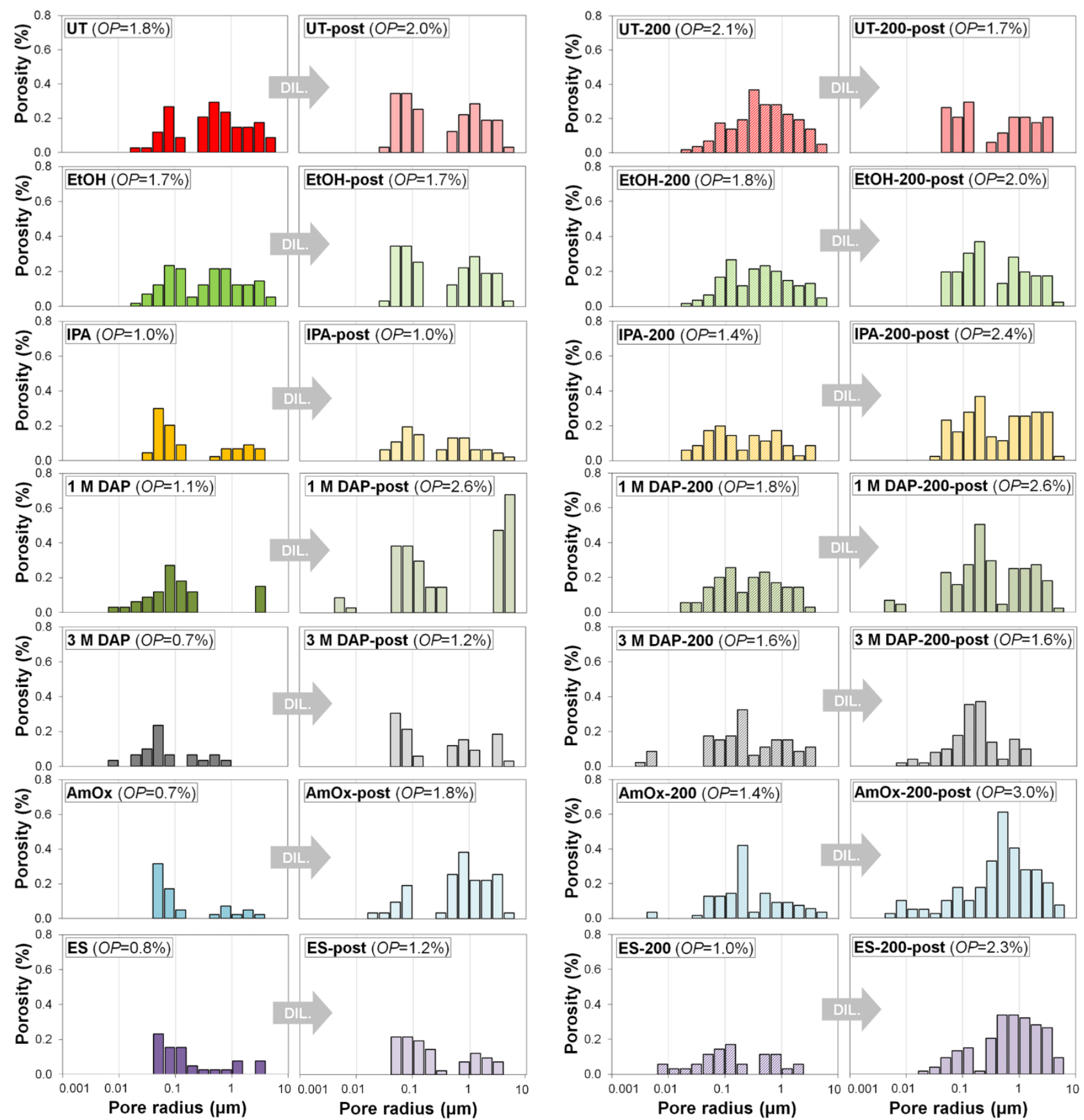

Fig. 7 Results of MIP tests on unweathered (left) and pre-weathered (right, "-200" suffix) specimens, before and after ("-post" suffix) 4 dry and 4 wet cycles in the dilatometer ("DIL."). 


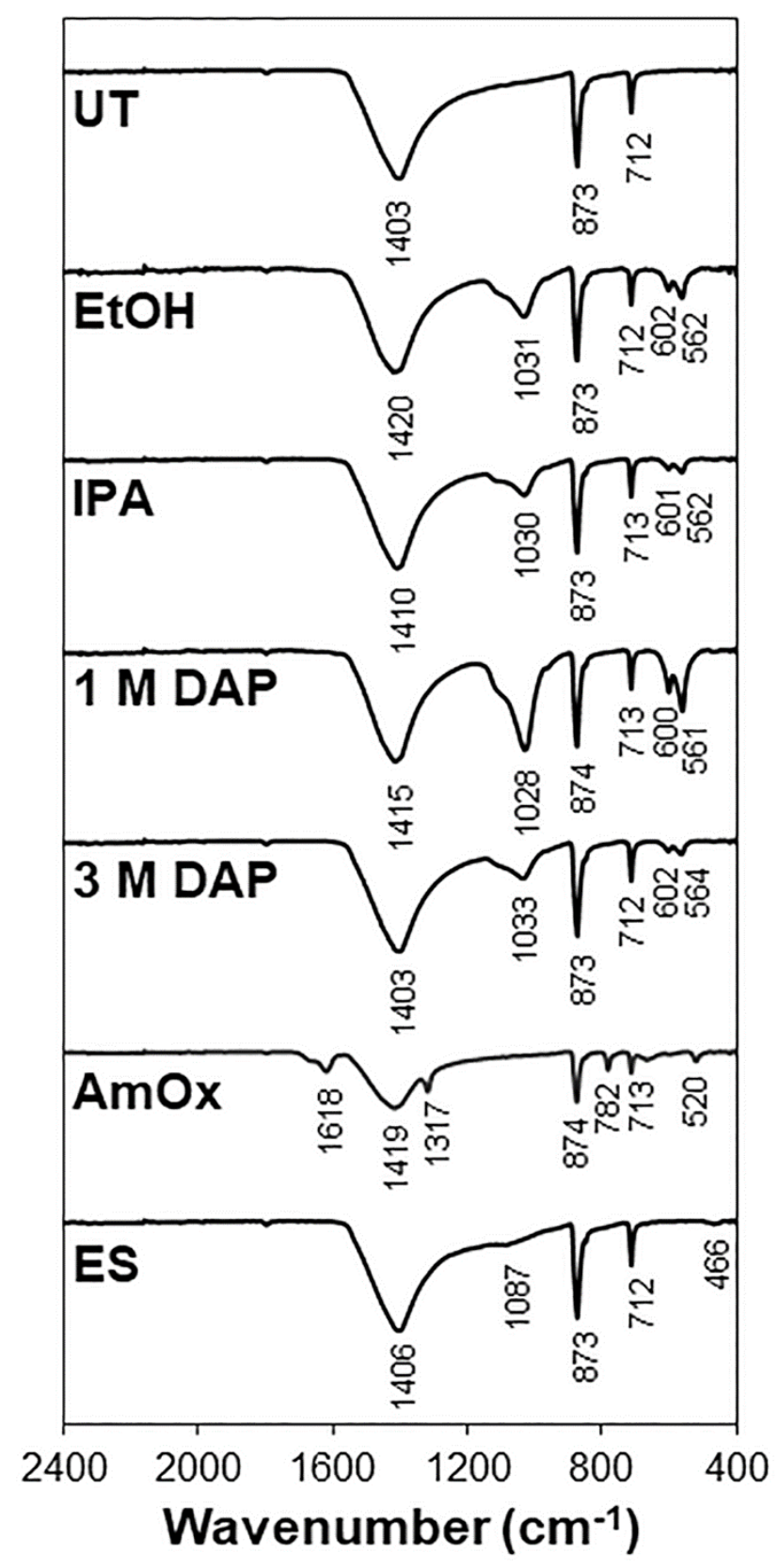

Fig. 8 FT-IR spectra of untreated and treated samples. 
This is a post-peer-review, pre-copyedit version of the article: Sassoni E., Andreotti S., Scherer G.W., Franzoni E., Siegesmund S., Bowing of marble slabs: can the phenomenon be arrested and prevented by inorganic treatments?, Environmental Earth Sciences 77 (2018) 387. The final version is available online at DOI: 10.1007/s12665-018-7547-7
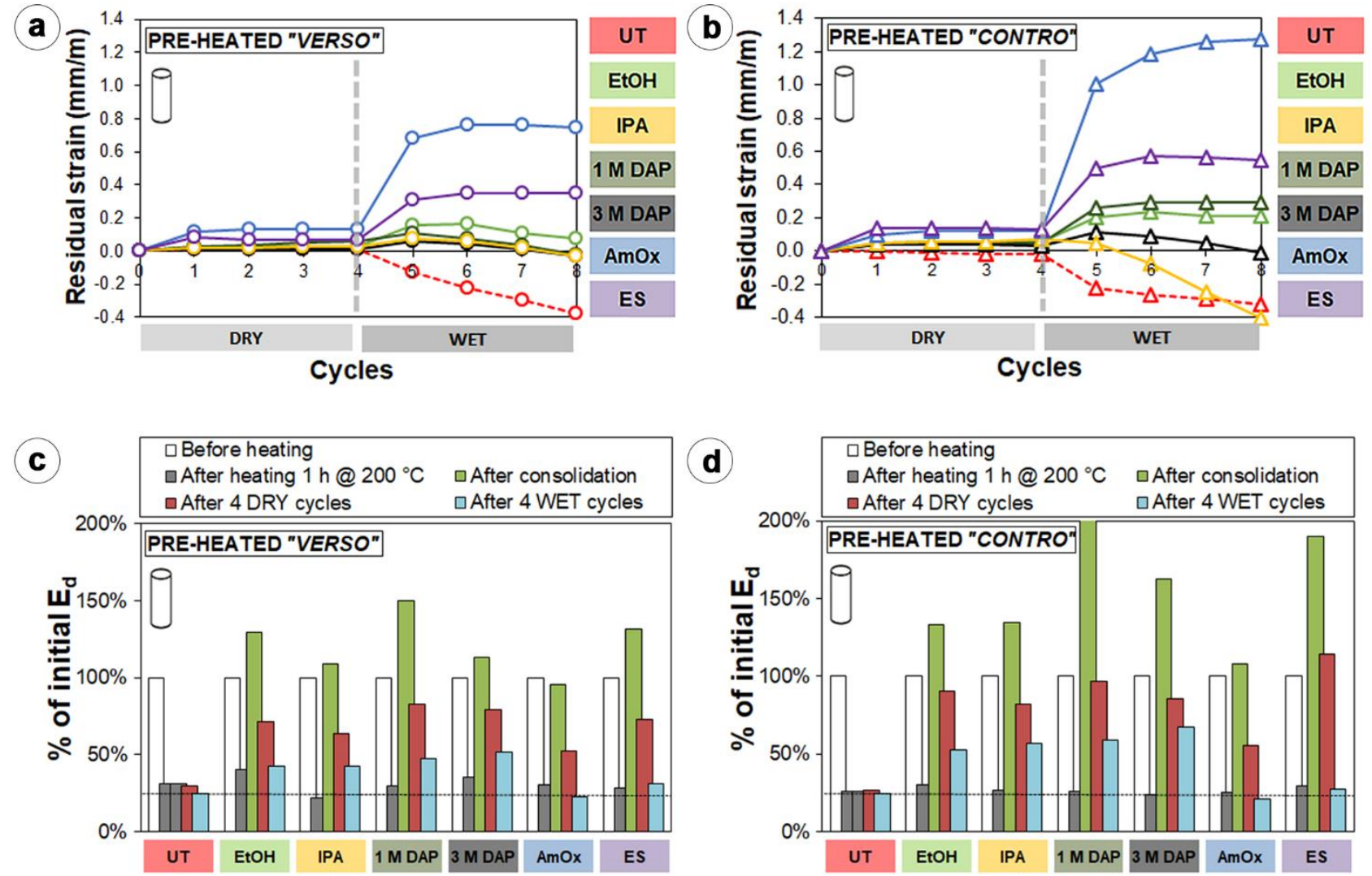

Fig. 9 Results of dilatometric tests on pre-weathered cylinders: $(a, b)$ residual strain and (c,d) $E_{d}$ variation in the "verso" $(\mathrm{a}, \mathrm{c})$ and "contro" (b,d) directions. 

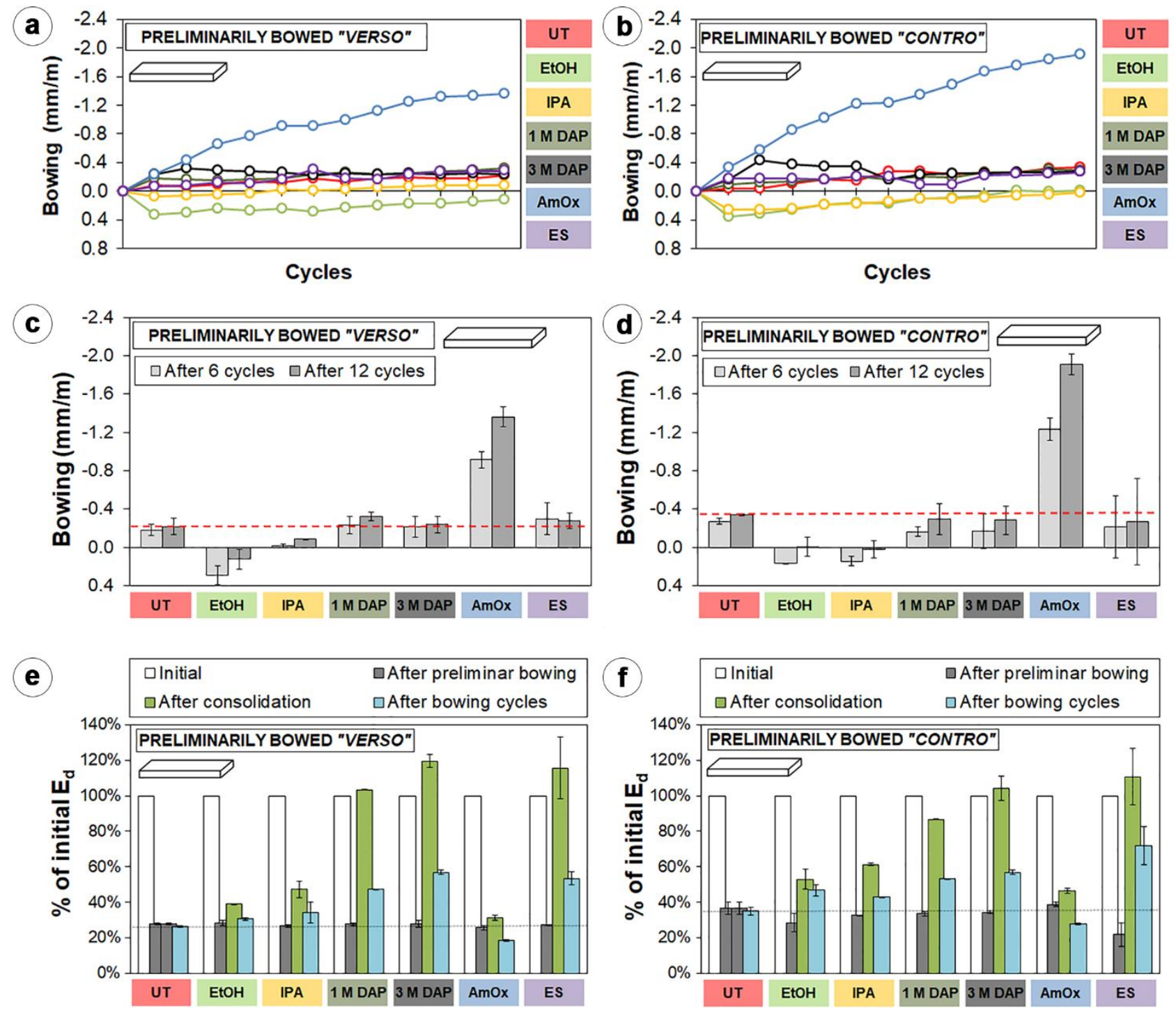

Fig. 10 Results of bowing tests on pre-bowed slabs (values are averages for 2 replicates, bars indicate the difference between the average and the maximum/minimum values)): (a,b) bowing as a function of the number of cycles, (c,d) bowing after 6 and 12 cycles and $(e, f) E_{d}$ variation in the "verso" (a,c,e) and "contro" (b,d,f) directions. 
This is a post-peer-review, pre-copyedit version of the article: Sassoni E., Andreotti S., Scherer G.W., Franzoni E., Siegesmund S., Bowing of marble slabs: can the phenomenon be arrested and prevented by inorganic treatments?, Environmental Earth Sciences 77 (2018) 387. The final version is available online at DOI: 10.1007/s12665-018-7547-7
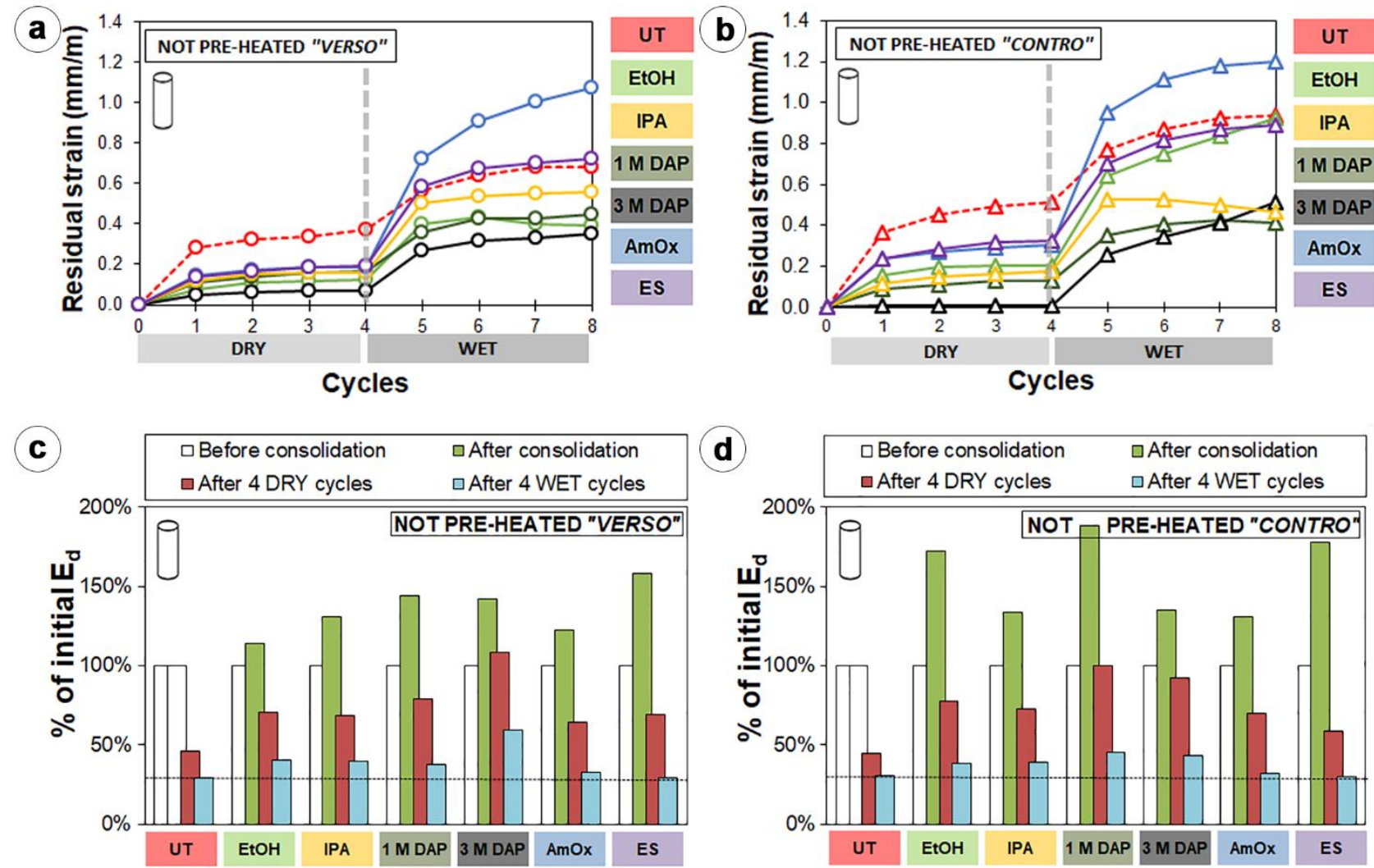

Fig. 11 Results of dilatometric tests on unweathered cylinders: (a,b) residual strain and (c,d) $E_{d}$ variation in the "verso" $(\mathrm{a}, \mathrm{c})$ and "contro" $(\mathrm{b}, \mathrm{d})$ directions.. 

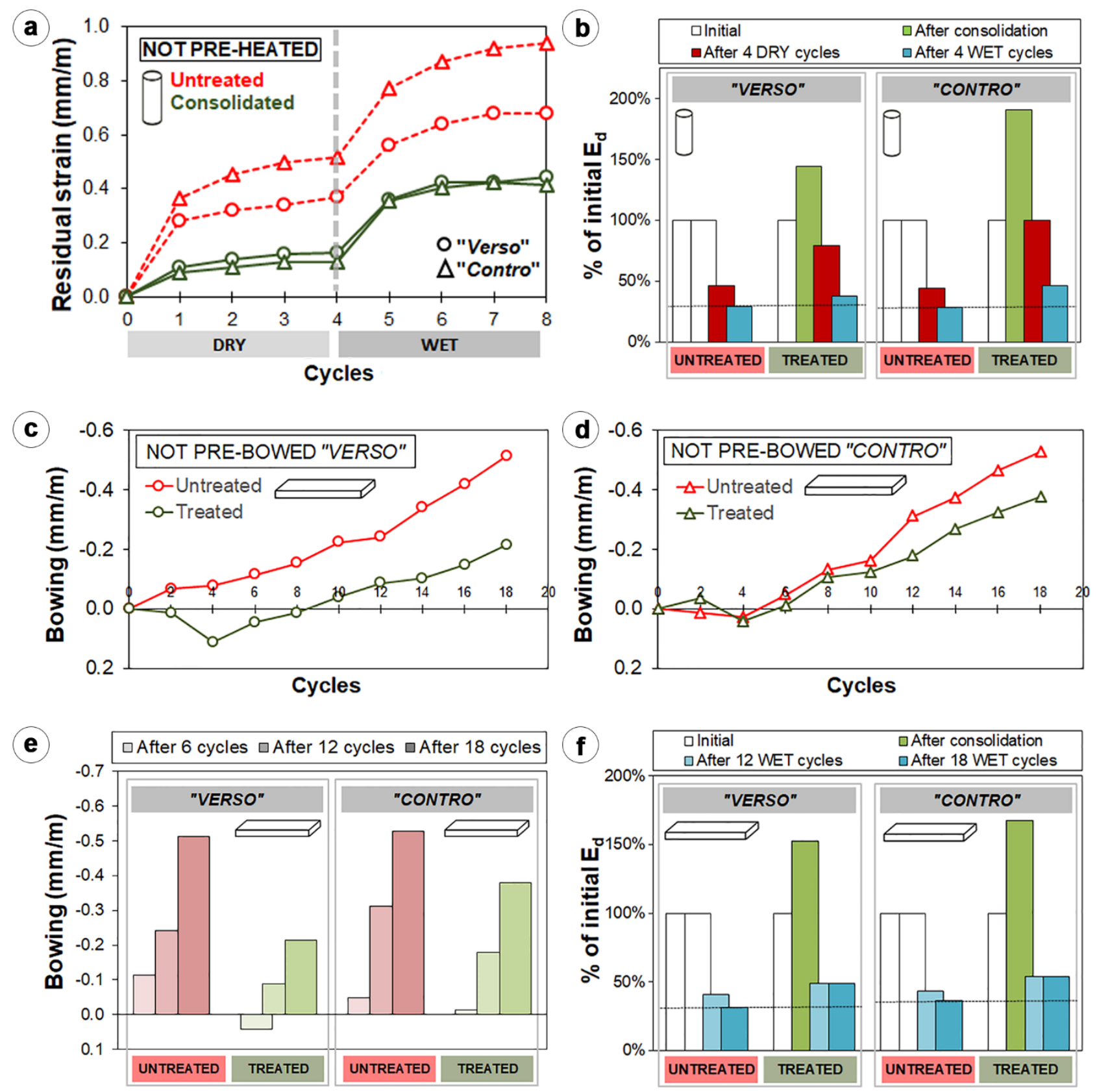

Fig. 12 Results of dilatometric and bowing tests on unweathered specimens, untreated and treated by "1 M DAP": (a) residual strain after dilatometric tests and (b) $E_{d}$ variation; (c,d) bowing in the "verso" and "contro" directions; (e,f) bowing after 6, 12 and 18 cycles and corresponding $E_{d}$ variations. 
This is a post-peer-review, pre-copyedit version of the article: Sassoni E., Andreotti S., Scherer G.W., Franzoni E., Siegesmund S., Bowing of marble slabs: can the phenomenon be arrested and prevented by inorganic treatments?, Environmental Earth Sciences 77 (2018) 387. The final version is available online at DOI: 10.1007/s12665-018-7547-7

\begin{tabular}{|c|c|c|c|c|c|}
\hline \multirow[t]{2}{*}{ Label } & \multirow[t]{2}{*}{ Description } & \multicolumn{2}{|c|}{ Pre-weathered } & \multicolumn{2}{|c|}{ Unweathered } \\
\hline & & Slabs & Cylinders & Slabs & Cylinders \\
\hline UT & Untreated reference & - & - & - & - \\
\hline $\mathrm{EtOH}$ & $0.1 \mathrm{M} \mathrm{DAP}+0.1 \mathrm{mM} \mathrm{CaCl} 2$ in $10 \mathrm{vol} \% \mathrm{EtOH}$ & 8 & 5 & - & 5 \\
\hline IPA & $0.1 \mathrm{M} \mathrm{DAP}+0.1 \mathrm{mM} \mathrm{CaCl} 2$ in 10 vol\% IPA & 8 & 5 & - & 5 \\
\hline $1 \mathrm{M}$ DAP & $1 \mathrm{M} \mathrm{DAP}+1 \mathrm{mM} \mathrm{CaCl}_{2}$ & 7 & 5 & 6 & 5 \\
\hline $3 \mathrm{M}$ DAP & 3 M DAP then limewater & 4 & 5 & - & 5 \\
\hline AmOx & $5 \mathrm{wt} \%$ ammonium oxalate & 6 & 5 & - & 5 \\
\hline ES & Ethyl silicate & 4 & 4 & - & 4 \\
\hline
\end{tabular}

Table 1. Label and description of the treatments and number of brush strokes to reach apparent refusal. 